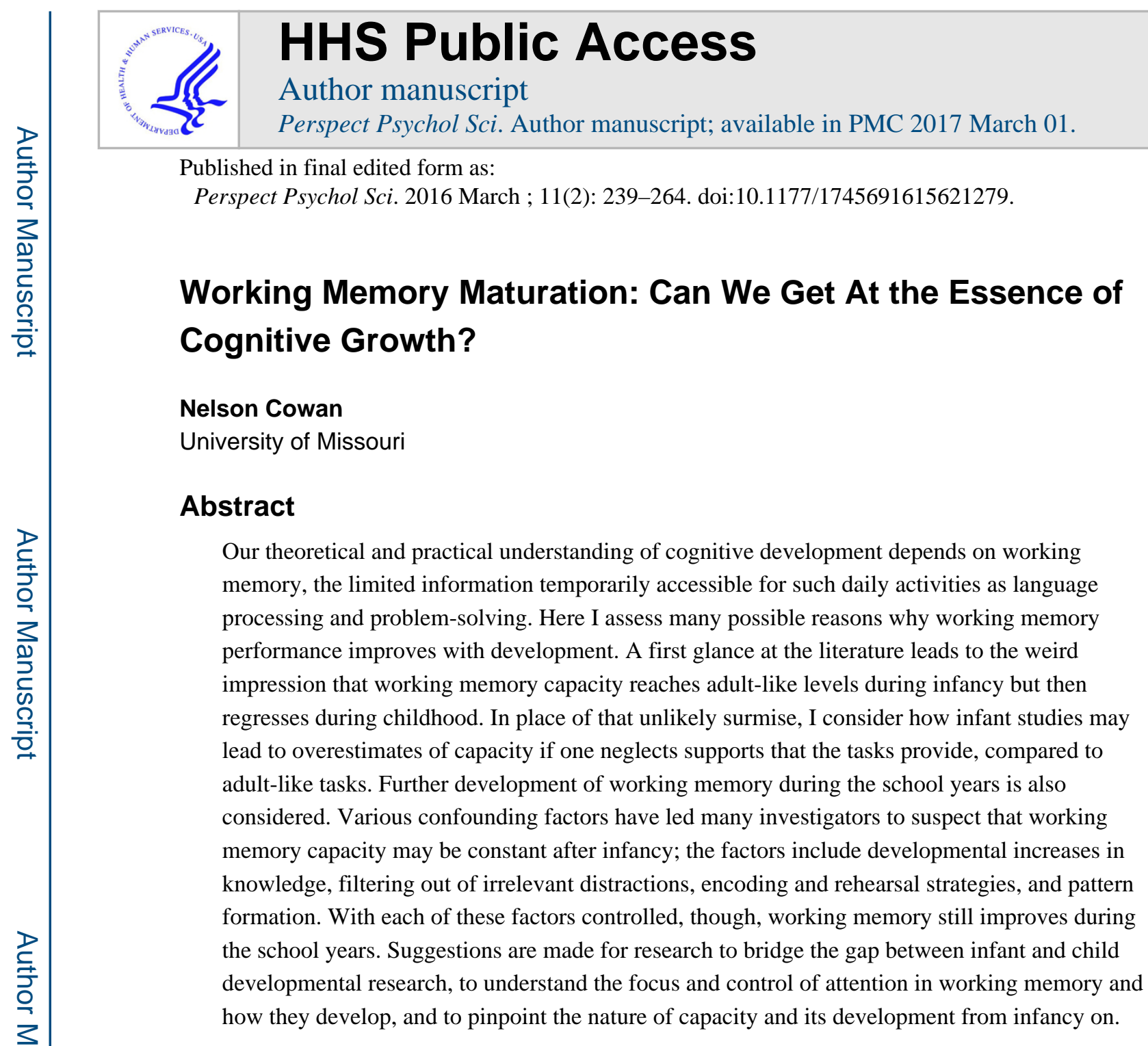

Few topics are more difficult to study than the development of fundamental processes in cognition. As the infant becomes a child and the child approaches adulthood, more facts are learned and more concepts are understood. More problems can be solved and more types of new learning become possible. More situations are coped with, and more strategies for coping with them are tried out and practiced. How is one supposed to zoom in to see what the contribution of a single factor to development may be, when so many entangled factors improve concurrently? Occasionally it is possible to find, say, a situation in which maturation occurs in the absence of further practice of a certain skill (e.g., Cowan \& Leavitt, 1987), but that type of situation usually seems unavailable to help separate out the basic factors of development. Therefore, extra care and effort are needed to try to understand cognitive growth, and in the present review I carefully attempt to understand the development of one key cognitive mechanism, working memory. The difficulties in doing so include (1) apparent contradictions between the results of procedures used with infants versus children and adults, and (2) a host of potential confounding factors.

Correspondence: Nelson Cowan, Department of Psychological Sciences, University of Missouri, Columbia, Missouri 65211, USA, Tel. 573-882-4232, CowanN@ missouri.edu. 


\section{The Issue of Working Memory Development}

Researchers of human development seem to agree on the importance of parameters of information processing, including working memory, the control of attention, inhibition of prepotent schemes, and self-regulation, in the developmental maturation of cognition. It seems clear within this general framework that a special role in cognitive development is played by working memory, the small amount of information that is currently highly accessible and available for cognitive processing. It includes the information in the conscious mind or available to it, and therefore refers to something quite central in cognition (e.g., Baddeley \& Hitch, 1974; Cowan, 1988; Miyake \& Shah, 1999). Many aspects of cognition vary depending on the working memory abilities of the child, and are compromised in children with various learning or processing challenges that can affect language comprehension and production, reading, mathematics, and problem-solving (e.g., Cowan, Elliott et al., 2005; Cowan, 2014; Cowan \& Alloway, 2009; Gathercole \& Baddeley, 1990; Jarrold \& Bayliss, 2007; Maehler \& Schuchardt, 2009; Siegel \& Linder, 1984; Siegel \& Ryan, 1989; Swanson \& Sachse-Lee, 2001). Working memory allows the retention of data needed to complete tasks, such as the retention of the early part of a sentence while putting the whole thing together or, in math, a digit to be carried to the next column mentally. Working memory also allows characteristics of a new situation to be considered so that an effective response can be programmed up; in that respect, working memory is key for fluid intelligence (e.g., Geary, 2004). The time seems right for an evaluation of recent evidence on why working memory develops. In this article, I will describe evidence against the adequacy of various common hypotheses, and suggest new ways to understand the literature.

Knowing why working memory performance improves would not only explain the basic finding of spans that increase with age across all tested types of working memory task (e.g., Gathercole, Pickering, Ambridge, \& Wearing, 2004); it would also help in various analyses of real-life cognitive tasks. Until we understand why working memory improves, we will not understand limits on how many operations can be carried out while the necessary data are held in mind (Case, 1995; McLaughlin, 1963; Pascual-Leone, 1970) or how many items can be interconnected to form a new concept (Halford, Cowan, \& Andrews, 2007). These questions stem from a neo-Piagetian viewpoint, in which the maturation of fundamental information processing parameters determines the capabilities and limits of cognition (Case, 1985; Commons, Trudeau, Stein, Richards, \& Krause, 1998; Demetriou, Christou, Spanoudis, \& Platsidou, 2002; Fischer, 1980; Halford, 1993; Pascual-Leone, 1970).

The expansion of working memory capacity can predict the development of cognitive aptitude (Andrews, Halford, Murphy, \& Knox, 2009; Pascual-Leone \& Johnson, 2011). One basis is that associations can be formed among items in working memory concurrently, up to a capacity limit of several elements, either deliberately (Halford, Baker, McCredden, \& Bain, 2005) or incidentally (Cowan, Donnell, \& Saults, 2013). As a simple, concrete example of the potential importance of working memory capacity for a young child's conceptual understanding, consider the folk definition of a tiger as a big cat with stripes. When forming the concept, if one forgets the large size, a common house cat could fit the bill. If one forgets instead that this animal must be a cat, it could be a zebra; and if one 
forgets instead the stripes, it could be a lion. The correct understanding of the concept thus involves concurrent consideration of at least three properties (large size, classification as a kind of cat, and the presence of stripes). It was on the basis of examples much like this that McLaughlin (1963) suggested an alternative to Piaget's stages of development, based on developmental increases in immediate memory, which would allow concepts of increasing complexity to be kept in mind and thus to be comprehended.

The present review is related in spirit to an earlier review that Dempster (1981) carried out on the development of memory span, the length of list that can be repeated without error. It was a review so penetrating that I found it informative when returning to it while completing the present effort. (In turn, Dempster owes a debt to Blankenship, 1938.) Dempster considered 10 potential sources of variation in the form of structures and strategies that might account for developmental and individual differences. For most of the potential sources of variation, it was concluded that there was not yet enough information; the one exception was the speed of item identification, said to be a source of change. The present review differs from Dempster not only in its reference to the subsequent 34 years of research, but also in orientation, in 5 ways. First, the present review is not limited to span or any one procedure, but roams across many procedures to gain insight into developmental change in the number of items that can be held in working memory. Second, whereas Dempster considered the serial order of responses, the present review focuses on the retention of items, generally without regard to their order. Third, whereas Dempster confined his review to children old enough to carry out a span task, the present review covers and attempts to reconcile two periods during which the most evidence has been accumulating in recent years: infancy, and the school years. Fourth, whereas Dempster was pessimistic about the notion of capacity or number of items kept accessible concurrently as a simple, potential mechanism of development, here that mechanism is revived and updated. Fifth, and finally, there is less concern here about which processes play some role in performance, and more of an assumption that many such processes probably do so. Instead, there is a more focused theoretical aim, to determine whether we need the notion of developmental change in basic capacity, or whether sources of variation such as knowledge and processing strategies can explain development even with capacity constant from infancy onward. That has been the question underlying much of my own developmental research published in the past 15 years.

\section{Outline of the Review}

In what follows, I start with a discussion of the history of research on the notion of working memory capacity and its development. Here I am talking about a construct that is more abstract and principled than just the level of performance on working-memory tasks. Second, capacity during infancy is examined, and is contrasted with child developmental findings. There are discrepancies between them in which infants look more capable than children, a paradox that can be resolved either by reinterpreting the infant research or by noting task demands in the child research that do not apply to the infant research. Third, reasons for the developmental progression during the school years are further examined, with various confounding factors controlled. Fourth, and finally, in the concluding remarks, 
a few additional suggestions are made for further research to clarify the nature of working memory capacity development.

\section{Theoretical and Empirical Background}

\section{A Brief History of Working Memory Capacity}

Definitions and origins-The term working memory was perhaps first used in psychology by Miller, Galanter, and Pribram (1960) to describe the organized collection of data and procedures that one must retain in order to plan and carry out actions. (The term was also used in computer science by Newell \& Simon, 1956). A bit later, the term working memory was used to describe a multi-component system in the human mind and brain that retains limited information temporarily while processing it (Baddeley \& Hitch, 1974). It is in that sense that working memory is explicitly supposed to have a limited capacity.

The term working memory is used in many different "flavors" by different investigators, as I learned when Miyake and Shah (1999) asked every contributor of their volume to define working memory. Some use the definition to describe the mechanisms involved. Thus, Baddeley (1986) included in the definition not only passive information-holding stores, but also central executive processes said to manipulate information in these stores (attentionshifting, updating of memory, inhibition of irrelevant information, etc.). According to that definition, short-term memory is just an outdated term that does not make distinctions between the parts. That nomenclature persists for many investigators. Perhaps the central executive processes were included within the definition of working memory because Baddeley and Hitch originally attributed memory storage capability to them, though that was no longer the case for Baddeley (1986). Some, such as Engle, Tuholski, Laughlin, and Conway (1999), have been most interested in the central executive or attention-based component and have tended to call it, alone, working memory, using the term short-term memory for the passive storage of information.

I use the term working memory in a rather theory-neutral sense, including as working memory any mechanism that helps hold information in a temporarily accessible state and provides a basis for ongoing cognitive processing, but excluding the processing itself from the definition. Others may then agree with the definition while disagreeing on the mechanism. In terms of the mechanism, I point to a focus of attention that can expand in scope to apprehend several items or chunks at once, or narrow down to concentrate on just one chunk, and activated elements of long-term memory (e.g., Cowan, Saults, \& Blume, 2014). Neurally and behaviorally the scope of attention, highly dependent on parietal areas of the brain, is said to be separate from the control of attention or central executive processes, highly dependent on frontal areas, with activated memory in various association areas (Cowan, 2011). Oberauer, Lewandowsky, Farrell, Jarrold, and Greaves (2012, p. 779) similarly characterize working memory as "as a system for holding a limited amount of information available for processing," even though their model of working memory is based entirely on interference processes, unlike Cowan et al. (2014). We included those processes but maintained that a multi-item attention focus also is involved. 
Empirical work on something like a limited working memory, albeit without reference to that particular term, goes back much further, to the beginning of the field of experimental psychology. It played an important role in the work of Wilhelm Wundt, who established the first experimental psychology laboratory around 1876 in Leipzig, Germany (Fancher, 1979) and helped inspire James (1890) to describe primary memory, the trailing edge of the conscious present. Around the same time, Ebbinghaus (1885/1913) carried out what has been considered the first research on memory, extensively on himself, trying to memorize lists of nonsense syllables and filing them away to test his memory later. The shortest list tried, 7 syllables long, was recalled correctly after the first repetition of the list, whereas the next-largest list, 12 syllables long, took on average over 16 repetitions. The 7-syllable list thus illustrated what Ebbinghaus (p. 33) called "first fleeting grasp" of a list, essentially immediate or working memory. Related investigations that were focused on immediate memory followed, including the rapid apprehension of several objects (Jevons, 1871) as well as memory span and its improvement with child development (Bolton, 1892; Jacobs, 1887).

Chunks as the units of working memory-Miller (1956) famously discussed the fact that there is a basic limitation in the capability of working memory, to about 7 items. This limitation was in stark contrast to the information-theoretic framework, which was popular at the time that he wrote because of its relevance for computers. The amount of memory in a computer is characterized in information theory by the number of binary choices that can be preserved, each memory location being switched on or off; human brains also make binary choices, when each nerve cell either does or does not fire in a given instant (McCullough \& Pitts, 1943). Working memory, though, does not work on a binary basis. English-speaking adults know 10 digits (i.e., slightly more than $2^{3}$ digits, or 3 binary choices) as opposed to well over 10,000 common words ( $2^{14}$, i.e., 14 binary choices), a difference of 3 orders of magnitude. Yet, Miller showed that the spans for lists of random digits or for lists of English words are both about 7 items. The items that count in working memory capacity appear to be familiar items or chunks; so for example, if one knows the acronyms for U.S. agencies IRS, $C I A$, and $F B I$, then the 9 letters contained in these acronyms can be remembered easily, in order, as a sequence of 3 acronymic chunks. The process of forming and using chunks does not depend on language, given that it has been shown to occur even in preverbal infants (Feigenson \& Halberda, 2008).

Under some circumstances, presumably when covert recitation can assist recall, capacity is affected by how long it takes to say each chunk (Baddeley, Thomson, \& Buchanan, 1975; Towse et al., 2005; Zhang \& Simon, 1985). However, a chunk capacity limit can be obtained rather cleanly by curtailing articulatory processing, in which case adults can retain typically only 3 or 4 chunks (Chen \& Cowan, 2009; Cowan, 2001; Cowan, Rouder, Blume, \& Saults, 2012).

There is a further current debate about working memory units that is beyond the scope of the present work, as its development has not been pursued sufficiently (though see Cottini et al., 2015; Riggs, Simpson, \& Potts, 2011). Specifically, there is a theoretical possibility that items are not simply present or absent from working memory, but present only to a degree, either because some of the features of the item have not been retained (Alvarez \& Cavanagh, 
2004; Awh, Barton, \& Vogel, 2007; Hardman \& Cowan, 2015) or because the memory of some continuous property, such as the angle of a line, is retained only imprecisely (Ma, Husain, \& Bays, 2014; Zhang \& Luck, 2008, 2011). This debate can be circumvented by talking about how many items can be remembered with sufficient precision to choose among alternatives, and memory for alternatives does seem limited to about 3 or 4 chunks in adults. A complex item like a Chinese character or colored shape may require multiple chunks. There could be developmental growth of precision: with development, representations could become more complete or precise, or the number of memory slots needed to encode a particular complex object could decrease. These possibilities will not be addressed directly here but they do figure into the developmental work that will be reviewed (cf. Kibbe, in press).

\section{Development of Working Memory Capacity?}

A simple and often-suggested basis of working memory development is an increase in the capacity of a holding mechanism that retains items in working memory, most notably the focus of attention (Cowan, 1988). In its simplest form, this working memory capacity growth could be expressed in the number of slots that can hold discrete items. However, the developmental logic is similar if maturation is thought of in terms of a fluid resource (e.g., energy) that can be distributed among items in such a way that, typically, only a limited number of items can be retrieved with enough precision to allow recall or recognition of categorically different items, and that number increases with age. I shall present an empirical base and then explore the theoretical ramifications of this idea.

Documenting working memory development-Many studies show increases in performance on short-term or working memory tests across ages in childhood. In this section we consider the simple hypothesis that with maturation, the number of separate chunks that can be held in working memory concurrently increases. Let us first document the developmental pattern, before trying to analyze what it may mean. The most extensive data set I know in which many types of test were administered across a wide age range using standard methods is from Gathercole et al. (2004). In Figure 1, I have rescored the means from their Table 1 to provide estimates of the number of items recalled, as described in the figure caption. Clearly, there is a steady improvement in performance from 4-15 years. Given that 15-year-olds approach adult levels of performance in other studies, this figure describes well the latter portion of the child developmental trajectory. Most of the measures are simple span measures requiring only reproduction of verbal or nonverbal stimuli, whereas three of the measures require processing also: reversal of the presented order (backward span), judging the veracity of sentences while remembering the last word of each (listening span), or counting dots within arrays while remembering the dot tallies (counting span). The developmental trend is similar across tests, except in two cases (visual pattern span and mazes), in which developing grouping processes may steepen the age trend as older children recode items to form a spatial configuration,.

Development of the number or size of chunks?-The number of items presented to the participant and then recalled need not equal the number of separate slots in working memory. A complex item might be converted to more than one chunk, whereas multiple, 
potentially related items might be combined into a single chunk. Therefore, the meaning of developmental increases in working memory performance can be known only if the units are known. At least two classic attempts were made to address this issue, but the results were discrepant. Dempster (1978) created word series with low word-to-word association values to limit chunking. Whereas digits yielded a $24 \%$ increase in span during the elementary school years, the specially-constructed word set yielded only a 5\% increase, suggesting that most of the developmental change came from improvements in chunking efficiency. In contrast, though, Burtis (1982) varied the opportunity for chunking by using letter pairs that were easy to chunk (e.g., MM), hard to chunk (e.g., FB), or intermediate (e.g., FM, as in a type of radio). The chunking manipulation was successful at all ages but nevertheless did not diminish age differences in performance. The discrepancies between these classic results point to the need for further study.

In a more recent research approach, the stimuli have lent themselves neither to rehearsal nor to chunking, because they were presented quickly, often in a simultaneous array. Estimates of working memory capacity from such procedures are typically in the range of 3 or 4 objects in adults (Cowan, 2001; Luck \& Vogel, 1998), with smaller estimates in preschoolers and children in the early elementary school years, about 2 to 2.5 items (e.g., Cowan, Nugent, Elliott, Ponomarev, \& Saults, 1999; Cowan, Elliott et al., 2005; Riggs, McTaggart, Simpson, \& Freeman, 2006; Simmering, 2012). However, some infant studies seem to suggest that infants retain at least 3 items, similar to adults (e.g., Ross-Sheehy, Oakes, \& Luck, 2003; Zosh \& Feigenson, 2015). These are not trivial discrepancies and they require explanation; they have not been reconciled in previous work. Dialogues between infant and child researchers are needed.

Neo-Piagetian theory-Piaget discussed the progression of children through various logical stages, but there was always a bit of tension within Piagetian thought. Task complexity and the memory requirements of the task clearly influenced performance on conceptual tests, a phenomenon called horizontal décalage (Piaget, 1977). Such findings were handled more gracefully by neo-Piagetian psychologists, who posited that fundamental information processing parameters like memory and processing efficiency improved with maturation. Better information processing in turn was said to allow more complex concepts to be comprehended, harder problems to be solved, and so on (Burtis, 1982; Case, 1985, 1995; Commons, Trudeau, Stein, Richards, \& Krause, 1998; Fischer, 1980; Halford, 1993; Halford, Cowan, \& Andrews, 2007; Demetriou, Christou, Spanoudis, \& Platsidou, 2002; Halford, Wilson, \& Phillips, 1998; Pascual-Leone, 1970). The processing parameter with perhaps the most impact was working memory, the small amount of information that can be readily accessed for completion of a task.

Even when children varied in their strategies for approaching a problem (e.g., Siegler, 1994), strategy selection and execution could be thought of as dependent on working memory capacity. The initial employment of a strategy that has promise may at first be cumbersome and attention-demanding, given that it is different from what the participant is used to but, with practice, the strategy can become less attention-demanding, and thus more helpful to performance (a change that has been documented for verbal rehearsal by Guttentag, 1984). The neo-Piagetian view would promote the idea that the growth of 
capacity is involved even in the conceptual, behavioral, and strategic changes that occur during infancy and early childhood, so it is of considerable importance to understand the nature of both the early and later child development of working memory.

\section{From Infancy to Childhood: Growth and Changing Task Demands The Working Memory Capacity Growth Hypothesis}

According to neo-Piagetian theories, the number of items that can be held in working memory (number of slots) governs how many schemes can be coordinated to produce a concept or motivate an action, and the number increases with development (e.g., McLaughlin, 1963; Pascual-Leone, 1970). Thus, from the mid-1960s until the mid-1980s, it was often suggested by cognitive developmental psychologists that processing and conceptual advances lead to performance advances. A child was ready to represent objects or people with words just after the child was able to remember that objects remained in existence even when hidden; typically this occurred within the first two years of life (Corrigan, 1978; Kahn, 1976; Moore \& Meltzoff, 1978). The ability to count could be linked to a concept of one-to-one correspondence (e.g., Greeno, Riley, \& Gelman, 1984). Basic science and mathematics understanding could be linked to conceptual advances such as conservation, the notion that, when matter is molded or poured into a different shape or cut into pieces, there is still the same amount of matter (e.g., Fischbein, 1987). Subsequent infant research, though, challenged neo-Piagetian thought.

Background of infant perceptual studies-Piagetian theory no longer dominates developmental work, largely because infants have been shown to engage in many types of thinking that, according to Piagetian theory, they should not be capable of, beginning with the ability to be surprised by a violation of object permanence as early as 5 months of age (Baillargeon, Spelke, \& Wasserman, 1985; Baillargeon \& DeVos, 1991). Whereas in the original research by Piaget and others, infants had to reach under a cloth to retrieve a hidden object, the newer research examined infants' reactions to an object's disappearance while it was behind an occluder. Infants, much younger than Piaget would have suspected, also have been shown to have some understanding of diverse properties of objects and events (e.g., that two objects cannot be in the same place at the same time: Baillargeon, Graber, DeVos, \& Black, 1990; Spelke, Breinlinger, Macomber, \& Jacobson, 1992). They show evidence of a mental faculty allowing enumeration of small numbers of objects (Wynn, 1996), transitive inferences (Mou, Province, \& Luo, 2014), and false beliefs (Choi \& Luo, 2015). Moreover, the bulk of research itself has largely shifted to the infancy period. In this research, infants are typically shown to be surprised by events that should not take place according to principles of the real world that infants previously had been assumed not to know.

The discrepancy between the quick acquisition of concepts according to the infant research and the much slower acquisition of concepts in child research (see Marti \& Rodriguez, 2012) led Keen (2003) to ask, about the representation of objects and events, "Why do infants look so smart and toddlers look so dumb?" The discussion naturally centered on differences in task demands in the infant versus child procedures. In one phenomenon, a ball essentially rolled down behind an opaque screen and should have come to rest when it hit a partition that extended up above the screen. On impossible-event trials, the ball instead 
showed up on the wrong side of the partition. Infants noticed the oddness of the impossible event according to the amount of surprise indexed by looking time. In contrast, in the toddler procedure, in which the child had to reach for the ball, evidence of knowledge of the ball's whereabouts did not emerge in two-year-olds. Nevertheless, these toddlers did pass the surprise test measured by looking time as in the infant procedure (Hood, Cole-Davies, \& Dias, 2003; Mash, Novak, Berthier, \& Keen, 2006). This research establishes the point that infant-child discrepancies can be linked to task demands.

Infant working-memory studies-A number of studies with different procedures suggest that the capacity of working memory dramatically increases between 6 months of age, when infants can respond well on procedures with only a single item to be remembered, and at most two months later, when infants can respond well on procedures with several items in a series or an array to be remembered (for reviews see Kibbe, in press; Oakes \& Luck, 2013; Zosh and Feigenson, 2015; Simmering, 2012). Moreover, these infants older than 8 months at some point appear to have a capacity of about 3 items, which is an adultlike number if one accepts the infant and adult procedures as equivalent. The 3 items apparently become individuated sometime around the end of the first year (Kibbe \& Leslie, 2013). This point needs careful scrutiny because children in the early elementary school years, tested with the adult-like procedures, seem to remember fewer items.

In one relevant infant procedure, Ross-Sheehy, Oakes, and Luck (2003) presented series of arrays on the left and right sides of the screen. On one side, successive arrays differed in one color, whereas the arrays presented to the other side were all identical. Six-month-old infants looked longer at the changing display only with 1-item arrays on each side, but ten-montholds did so with 4-item arrays, comparable to what is found with adults using the adult procedure. This result was not obtained in these infants using 5-item arrays. The correspondence with adults' capacity could be a coincidence, inasmuch as adults appear to have a capacity that actually reaches an asymptotic level closer to 3 items (e.g., Cowan, Fristoe, Elliott, Brunner, \& Saults, 2006; Rouder et al., 2008; Zhang \& Luck, 2008); no one suspects that infants have a higher capacity than adults. In the infant procedure, perhaps not every change is detected, but still enough of them to attract attention. In any case, there are a larger number of recently-activated colors in the changing side of the array, automatically attracting attention.

The possibility of an overestimate of capacity with a multiple-look procedure was eliminated in later work by Oakes, Baumgartner, Barrett, Messenger, and Luck (2013). On every trial, the infant saw an array only once, followed by another array that gave the infant a choice of looking at an item that came from the array, versus another item that was new. For arrays with two unique objects, 8-month-old infants looked for more time at the novel item, indicating the ability to remember the array, whereas 6-month-old infants could do so only with arrays limited to one object. The 8-month-olds' proportion of looks to the changed square, it should be noted, was not very high: it hovered around .60.

Kibbe and Leslie (2011) found that when infants of 6 months see two objects disappear behind occluders, they are surprised when an occluder is raised and the object is missing, but not when the object that appears is the wrong one, the one that had disappeared behind the 
other occluder. The implication is that even 6-month-old children have rudimentary multiple-object representations, but not including the details of the individual objects. The progression of infant findings suggests that object-file representations are quite basic but that the details of these objects are filled in with maturation in infancy. In the study of Kibbe and Leslie, infants may only have remembered that the occluders had objects behind them.

The change between 6 months and several months later may have to do with the individuation of objects. Ross-Sheehy, Oakes, and Luck (2011) used a multiple-exposure procedure and found that when there was a moving pre-cue (inasmuch as one array item rotated), even 5-month-old infants preferred the stream in which the rotating object changed color from frame to frame, compared to the stream in which the rotating object remained the same color (as did all of the objects). In contrast, when there was no such salient pre-cue, 6month-olds apparently perceived the array without separating the objects.

In the aforementioned studies, the looking responses might be considered automatic rather than deliberate. In a procedure suggesting that infants already have acquired the ability to think of 3 items in working memory deliberately, Feigenson and colleagues have conducted a series of studies well-summarized by Zosh and Feigenson (2015). When 13-month-old infants are shown attractive objects that are then hidden in a box, they search for the objects, up to a point. They will often search for up to three identical objects. If four such objects are hidden, however, the process breaks down and infants act as if they have forgotten that multiple objects are hidden. This catastrophic forgetting does not take place, though, if the objects are different from one another. In that case, the infants typically search for up to three of the four items and then stop. Apparently, simply suggesting a developmental increase in the number of items in working memory is not going to be sufficient to explain the transition from infancy to adulthood.

At this point, however, we must think carefully about exactly what infants are doing in the procedure of Zosh and Feigenson (2015), when they remove 3 of 4 items hidden in a box and then stop. A default hypothesis might be that they hold 3 items in working memory and pull out items from the box until they find all of the ones included in working memory; but that hypothesis cannot explain the findings. On most trials in which it is assumed that 3 items are in working memory, the first 3 items removed from the box will not be the same 3 as are held in memory, so the fourth item should be pulled from the box. In fact, the obtained results are more like what would be expected if infants held only 2 items in memory and compared these items to the ones drawn from the box. Suppose, for example, that Objects A and B happen to have been stored in memory, whereas Objects C and D have been lost from memory. All four objects are entered into the box. When they are drawn out in random order, there are 24 equiprobable orders in which 4 items could be drawn. The objects in working memory are drawn out within the first 2 draws in 4 of those orders $(A B C D, A B D C, B A D C$, and $B A D C)$ and the recovery of objects will be discontinued after the first 2 draws. The objects in working memory will be drawn out in exactly 3 draws in 8 of those orders ( $A C B D, A D B C, B C A D, B D A C, C A B D, C B A D, D A B C$, and $D B A C$ ) and the process will be discontinued after the first 3 draws. Finally, in the remaining 12 orders, all 4 draws will be needed in order for the infant to retrieve the specific 2 items in working memory; either Object A or Object B is drawn fourth. Summing across all instances, the 
expected mean number of draws would be $(2 \times 4+3 \times 8+4 \times 12) / 24$ or 3.33 draws. We can conclude that either the infants in fact retained an average of slightly under 2 items in working memory, or else a different process was used by the infants to determine when to stop withdrawing objects from the box. We will discuss one possible alternative process in the following section of the article, related to Figure 2.

Note that there may be some difficulty in reconciling infant and child results experimentally. It is possible to use infant procedures with children, but superior performance in children compared to infants might not be theoretically decisive. For example, a 10-year-old might succeed at the task of Zosh and Feigenson (2015) with four hidden items or more by counting items as they disappear into the box (e.g., Gelman \& Meck, 1983), and might succeed at the procedure of Oakes et al. with five array items by systematically examining one item or more until a change is detected. This superior performance in children compared to infants still might not be taken as evidence of a larger basic capacity in children, but rather the development of secondary skills such as counting. It may be that toddler research is especially needed to bridge most meaningfully the infant and child results on basic working memory capacity (e.g., Keen, 2003; Simmering, 2012) because they do not yet have advanced strategies like counting that are not considered in the test rationale. In any case, the hypothesis that the number of items in working memory simply increases with age remains viable, but has not been proven.

\section{Hypothesis of Control: Automatic and Deliberate Maintenance in Working Memory}

According to another hypothesis, the proposed difference between infant and adult procedures is not in how many items can co-exist in the core part of working memory, but in how appropriately the contents can be controlled (cf. Kane \& Engle, 2003), and thus the correct memoranda maintained, as the stimuli change across the experimental trial. Theoretically, this might occur because of how two different kinds of working memory described by Cowan $(1988,1999,2005)$ are used, namely the activated subset of long-term memory, and the focus of attention (Figure 3). According to this embedded process model, incoming stimuli from the environment automatically activate physically-based features (tone pitch and loudness, brightness and line orientation, color, taste, touch, etc.) and sometimes activate some semantic, abstract features as well (phonemic categories distinguishing one word from another, word meanings, object identities, connotations, etc.). These activated features are subject to decay over time (Ricker \& Cowan, 2014; Darwin, Turvey, \& Crowder, 1972; Sperling, 1960; Treisman, 1964) and subject to interference from subsequent input with similar features (Nairne, 1990). In contrast, the focus of attention is limited to at most a few objects at once, producing integrated ensembles of features for those objects (cf. Kibbe, in press) and allowing a more complete semantic analysis of the objects or events. Features of items in the focus of attention remain activated temporarily after these items are no longer in focus. When I talk of working-memory capacity limits, I am referring specifically to how many items can occupy the focus of attention.

Presumably, deliberate actions that include head-turning or eye movements as well as manual movements and speech all emanate from the focus of attention. There are, however, two ways in which information can get into the focus of attention and can result in actions. 
In the first, the automatic route to action, incoming stimulation is seen to be discrepant from the neural model of prior stimulation, and it attracts attention. This can occur for stimuli for which there was no prior attention. For example, a thunderclap can draw attention away from some ongoing attended activity. It can also happen in a more extensive way for attended stimuli. For example, if a stranger seen by a young child is a man wearing a kilt and the child has never seen anything like that before, the novel combination of man-withskirt may attract attention.

Second, in the deliberate route to action, attention is governed by central executive processes. In verbal individuals, we sometimes can be sure that central executive processes are involved because responses can be altered according to instructions; but it is assumed here that manual responses in preverbal infants also can be deliberate and based on central executive processes. It is also possible for the deliberate route to override the automatic route to control head and eye movements, even in infants (e.g., Johnson, 1995).

The route that is used to make a response sometimes is critical for understanding responses in working memory tasks (and other tasks as well). It can be important when the automatic and deliberate routes bear information that is discrepant, with the automatic route provoking a wrong answer unless the deliberate route overrides it. One important example is the presence of proactive interference. There are cases in which a certain feature is absent from a set of items studied on the current trial, but present in a recent, previous trial. According to the automatic route, there may be a feeling of familiarity worth attending to, but the deliberate route is able to use information indicating that this familiarity (from a previous, recent trial) is not the kind of signal one wants to act on in the trial. Sometimes the automatic route leads to a prepotent response that one wishes to avoid (e.g., Kane \& Engle, 2003). As I will discuss, the infant procedures may not elicit the deliberate route to the same degree as the adult procedures.

Background: controlled information maintenance in adults-Consider a typical trial in the often-used, array comparison procedure (Luck \& Vogel, 1997). In one version of the procedure, the probe array is a repetition of a briefly-studied array of colored squares except that one item is marked (e.g., with a surrounding circle), and that item may have changed to a different color. The task is to indicate whether the marked item has changed color. If so, it can cause a discrepancy from the neural model of the environment, attracting attention. However, for several reasons, that attention signal is not a reliable indicator that the item has in fact changed. To some extent, recognition of an item that was in the memory set also attracts attention, just not as much as a novel item. Moreover, the attraction of attention to a changed probe item might well be diminished if the neural model of the world is not limited to the present trial. Suppose, for example, that green was a color present in the studied array on Trial $n-1$ but not on Trial $n$, and that the marked item in the probe array on Trial $n$ is green. If green is already in the current neural model from the prior trial, the marked item may not evoke a sense of novelty and the automatic system will not provide a helpful attention signal indicating that the marked item was not in the present, Trial $n$ array. This outcome would be an example of proactive interference, which has been documented in such array tasks (Shipstead \& Engle, 2013). 
In the deliberate system, items are kept as much as possible continually in the focus of attention, or are drawn back into focus as often as possible, precisely to avoid such proactive interference. For example, Cowan, Johnson, and Saults (2005) presented word lists followed by a probe word, the required response being to indicate whether the probe word was present in the list. When the correct answer was "no," the probe word sometimes matched (or resembled) a word presented in a recent trial. With lists of 3 or 4 items, short enough to be held in the focus of attention, there was very little incorrect responding on the basis of the recent lure (i.e., very little proactive interference), but much more proactive interference was obtained with longer lists of 6 or 8 items that presumably could not be held in focus.

In the adult array change-detection procedure, if we assume that memory can be accumulated across more than one trial, there may be no reliable familiarity signal indicating that a change is present or absent. What the participant must then do is to keep the memory set in the focus of attention while comparing the relevant item to the marked probe. This procedure is illustrated in the top panel of Figure 4 for an unchanged probe and in the middle panel of that figure for a changed probe.

Information maintenance in infant procedures-According to this informationmaintenance hypothesis, infants of 8 or 9 months are already able to focus attention on 3 items and establish the corresponding activation of their features in memory. However, infants and young children would not be able to use the deliberate system adequately to separate the stimulus stream into discrete events, only some of which should be used to motivate the response (e.g., the stimuli from the studied array on the present trial). Unlike the adult procedures, the infant procedures may not require use of that deliberate system.

Even in the "one-shot" procedure of Oakes et al. (2013), infants do not face one problem that the adults usually face in visual array memory procedures. In the infant procedure, a familiarity signal can indicate that one choice is more familiar than another, and thus more active in memory, even if the items are not in the focus of attention (Figure 4, bottom row). In the adult procedure, this is not possible because only a single probe is presented; it will give rise to a certain signal of familiarity, but there is nothing to compare it with. The result must be based on recollection of the probe as present or absent from the studied items on the present trial.

In contrast to the usual adult procedure, but similar to Oakes et al. (2013), Cowan, Rouder, Blume, and Saults (2012) offered adults two response choices on every trial, one of which was taken from a studied list of words. In this procedure, a familiarity signal should be useful as the studied word should be more familiar on average. The findings in this study indicated that performance was better than one would expect on the basis of short-term capacity alone; a component of activated long-term memory had to be added to explain the results. The array situation may be different, though, inasmuch as any capacity limit would strongly apply during encoding of the briefly-presented array; in list recall, memory is loaded more gradually. Thus, it could be an important comparison to try the Oakes et al. procedure on adults. 
The pattern observed by Zosh and Feigenson (2015), in the procedure in which objects are hidden in a box and can be retrieved by the infant, also can be understood in the embeddedprocess view if the focus of attention can include 3 items in these infants. When a fourth identical item is presented, it replaces an item in the focus. Therefore, the infant may be happy with 3 items even though these may differ from the 3 items originally encoded into working memory. That is, a direct comparison of items in working memory with items retrieved from the box is not carried out by the infants. According to this suggestion it can be predicted that, if Item 4 is then retrieved from the box by the experimenter, it should elicit less surprise than if an entirely new item were retrieved from the box. That is the prediction because Item 4, while no longer present in the focus of attention, is often still present in the activated portion of long-term memory. The focus of attention is presumably limited to 3 items at once but, still, each item that emerges from the box can be compared to the potentially larger number of recently-presented items in activated memory, and a mismatch caused by a novel object may recruit attention. Thus, the suggestion is to combine the object-retrieval procedure with an interest/looking phase on some trials, in future work.

The top row of Figure 2 graphically illustrates why it is implausible to propose that the infant in the procedure of Zosh and Feigenson (2015) uses the focus of attention to compare the retrieved objects to the objects in memory. In the example, an infant has retained three of four hidden objects in memory. On $75 \%$ of the trials, by chance, the retrieved object will not match all of the objects in working memory, and it does not match in the example shown. If there were a comparison process, the infant would still wonder what happened to one of the objects in working memory, Object B in the example. The second row of the figure shows an alternative processing mode in which the retrieved object that was not in working memory now displaces one of the objects that was in working memory. When the infant has retrieved 3 objects, those objects will fill the focus of attention and the infant will be satisfied with the items reaped and will not notice the mismatch between the set stored originally in the focus of attention and the current set in focus.

Childhood development of information maintenance-The developmental trend in working memory that we have seen during childhood could occur because young children are deficient compared to adults in the deliberate process of preserving items in the focus of attention while comparing them to the probe item. Such a process would be consistent with the report that a postcue can be used to draw array items back into the focus of attention less successfully in 7-year-olds than in older children or adults (Shimi, Nobre, Astle, \& Scerif, 2014). The finding may also be compatible with the dynamic systems view of development, in which parameters of activation and inhibition mature to produce more stable representations in working memory with age (Schutte \& Spencer, 2009; Simmering \& Patterson, 2012). The notion would be that although 7-year-olds may hold in mind as many items as older children or adults, in the younger children the process of comparing an array to a probe would create interference that would tend to knock out of working memory some of the intended memoranda, resulting in poorer performance than in the older participants. Similarly, in recalling a list, recall of some items would create output interference that could prevent the recall of additional list items, if attention-based processing was not sufficient to preserve the items not yet recalled. 
What is the nature of controlled information maintenance?-It is not clear what processes are involved in the deliberate maintenance of information in the focus of attention but there is considerable work suggesting that in individuals older than about 6 years of age, the focus of attention rapidly circulates to refresh various items in turn. The number of items that can be recalled is reduced in a linear fashion as a function of the cognitive load, the proportion of time during the input of the list taken up by an interleaved distracting task (Barrouillet, Portrat, \& Camos, 2011). This is presumed to occur because capacity is limited to the number of items that can be refreshed by attention before becoming inaccessible to the refreshing process because of rapid temporal decay of the memory representations. Gaillard, Barrouillet, Jarrold, and Camos (2011) found that working memory performance differences between third- and sixth-grade children were eliminated when the amounts of time available for each part of the task were increased for younger children by an amount commensurate with their slower processing and refreshing times. This finding suggests that refreshing rate is a major basis of age differences in working memory, and it could be the basis of controlled memory maintenance.

Camos and Barrouillet (2011) found, moreover, that at age 6 and below the cognitive load relation did not hold and, instead, information was lost as a function of time rather than cognitive load, suggesting that children that young do not engage in the same maintenance process of refreshing the items in the focus of attention. They instead let the information degrade over time. It is therefore possible that children younger than this maintain information only in the activated portion of long-term memory, with information shifting in and out of the focus of attention in an unprincipled way. Children older than 6 years would progress with age in the rate of systematic refreshing of information, and thus the amount that can be maintained in the face of interference.

An alternative to the decay-based interpretation of refreshing is that there is a limited processing cycle time, within which all working memory items that are going to be retained must be activated in a serial manner (e.g., Lisman \& Idiart, 1995). There is evidence that there indeed may be a processing cycle within which some kind of refreshing may operate (Fiebelkorn, Saalmann, \& Kastner, 2013; Lisman \& Jensen, 2013; Siegel, Warden, \& Miller, 2009) but there is as yet little developmental evidence related to this alternative.

\section{Infancy to Childhood: A Summary}

In sum, there are motivations for new research to determine whether the development that occurs during infancy and its transition to childhood involve increases in the number of items held in attention-based working memory, its scope; whether it is not the scope but attentional control that develops, allowing stable maintenance of the most relevant items in a wider range of circumstances; or whether both the scope and control of working memory develop. Scope and control appear partly independent, as shown for example by Cowan, Fristoe et al. (2006). 


\section{Development throughout the School Years: Controlling Confounding Factors}

The interpretation of childhood developmental results depends critically on the infant research and its proper interpretation. If the similarity in apparent working memory capacity of infants and adults is born out, then there is no room to anticipate developmental changes in capacity during childhood. Instead, the childhood development would have to be related to how children handle the additional demands that the adult-like procedures entail (presumably, control of working memory contents). If infants actually are shown to retain fewer items or chunks than adults, then it becomes more likely that there is further, childhood development of capacity also.

Although this fundamental question cannot yet be answered, we can ask about the task demands of adult-like procedures to determine what confounding factors other than capacity or control of the contents of working memory could account for the developmental improvement without reference to capacity. The capacity-growth theory benefits if we can experimentally control various mechanisms that change with development, and still find maturational growth in the number of items that can be retained in working memory. This research strategy has been used by some who have concluded that mechanisms other than capacity do totally account for the improvements (Case, Kurland, \& Goldberg, 1982, identification time; Dempster, 1978, chunking efficiency; Gaillard et al., 2011, attentionbased refreshing rate), and others who have concluded that these confounding mechanisms do not have that impact (Burtis, 1982, chunking efficiency; Cowan, Elliott et al., 2006, speaking rate; Hulme \& Muir, 1985, rehearsal rate). This strategy has not been used much lately but is the mainstay of my recent developmental research.

Figure 5 shows measures drawn from several of my studies in such a way that a common comparison can be made across two age groups: children 6-9 years old, and adults. The top panel of the figure shows that, in all of the studies noted, there is evidence that adults yield estimates of the number of items stored in working memory that exceed the estimates for the children. The bottom panel of the figure shows that, in each case, a measure of the efficiency with which working memory information is processed does not differ between the two age groups in the tasks used in these studies. This increase in capacity (or perhaps mental attentional energy: Pascual-Leone, 1970) is as the neo-Piagetian approaches would suppose (e.g., Case, 1995; Halford, Cowan, \& Andrews, 2007; Pascual-Leone \& Johnson, 2011). Below, details about each of these factors is explained.

\section{The Factor of Increasing Knowledge}

Evidence for the effect of increasing knowledge-Knowledge can allow multiple stimulus items to be combined to form fewer meaningful chunks of information. Chi (1978) showed that knowledge is critically important for working memory. Children (third through eighth grade, mean age 10.5 years) who were expert at chess were better able to remember chess board configurations than were naive adults, even though the usual adult superiority emerged for memory of lists of digits. The case for knowledge was furthered by a seminal paper by Case et al. (1982). They examined the ability to recall lists of ordinary, spoken, 
English words, and the speed of repetition of individual words within the set, finding both measures to be poorer in the children 3-6 years old than in young adults. However, when adults received unfamiliar nonsense words instead of English words, their performance on both measures resembled the children with English word stimuli. This finding suggested that the operational efficiency of working memory increases with familiarity with the materials, presumably accounting for the developmental increase in working memory performance.

Cowan, Ricker, Clark, Hinrichs, and Glass (2015) argued, though, that the Case et al. (1982) results cannot necessarily be attributed to knowledge as an alternative to capacity development, but possibly knowledge in combination with capacity development. That could be the case, for example, if the nonwords presented to adults must be encoded as more than 1 chunk each. For example, the nonword item meeth as a novel combination might often have to be remembered as two chunks, perhaps "mee+th" or " $m+e e t h$." If so, adults studied by Case et al. could have been superior to the children in the number of perceived chunks held in working memory, even if the two groups were in effect equated in the number of experimentally-defined items in working memory.

\section{Working memory development in childhood with knowledge controlled-To} examine the role of memory with knowledge controlled, Gilchrist, Cowan, and NavehBenjamin (2009) used verbal sentence materials. Children in Grades 1 and 6 (who are 7-8 and 12-13 years old, respectively) and adults were tested with spoken sentences that were easy for all age groups in the study to understand, e.g., Thieves took the painting; our neighbor sells vegetables. These sentences were then combined to form lists of sentences that did not tell any coherent story. The task was to repeat the list of sentences verbatim. It was supposed that each sentence would typically be represented as a single chunk, but that the sentence-long chunks would be retained separately in working memory. There were two key measures. First, a processing efficiency measure was chunk integrity, defined as the number of words recalled from a sentence, conditional on at least one content word being recalled from that sentence. That measure showed about .80 chunk integrity in each age group, so the developmental improvement in memory could not be explained by a change across age groups in chunk integrity. Second, there was a measure of chunk access, the number of sentences for which at least one content word was recalled. Given that the integrity of each sentence as a chunk was high, it appeared that this measure of chunk access could estimate how many sentences (i.e., chunks) could be recalled mostly intact. This measure showed a developmental change (e.g., in a condition with 8 unrelated sentences per trial, an increase from about 2.5 chunks in first-grade children to about 3.5 chunks in adults). The apparent developmental increase in capacity in this procedure, despite the developmental constancy of sentence knowledge for these materials, is illustrated in the leftmost clusters of bars in Figure 5 (capacity, top panel; processing efficiency, bottom panel).

Cowan, Ricker et al. (2015) set out to determine whether knowledge is sufficient to explain developmental changes in visual memory, using a modification of an array memory procedure developed with adult participants by Luck and Vogel (1997). The stimuli to be remembered on each trial of Cowan, Ricker et al. were briefly-presented arrays of either five English letters, or three unfamiliar characters (shown in Figure 6). Given the superiority of 
the recall of letters, the difference in array size allowed the two stimulus sets to produce more similar levels of performance. The participants were children in Grades 1-2 (6-8 years old), Grades 3-4 (8-10 years), Grades 5-7 (10-13 years), and college students. On each trial, the array to be remembered was followed $1 \mathrm{~s}$ later by a masking pattern, a retention interval of 1,5 , or $10 \mathrm{~s}$, and then a probe item in the same spatial location that one of the array items had occupied, to be judged the same as the array item in the corresponding location or not found in the array.

Results of this study were scored in terms of a formula to estimate the number of items in working memory, taking into account guessing (Cowan, 2001). The formula was based on the assumption that an individual has $k$ items in working memory on each trial and, if the array item at the probed location is in working memory, the individual knows whether the probe differs from the corresponding array item. If the item is not known, the participant must guess. The resulting formula is $k=S(h-f)$, where $S$ is the number of array items, $h$ is the proportion of change trials in which there was a hit or correct detection of the change, and $f$ is the proportion of no-change trials in which there was a false alarm. If the development of working memory were totally the result of knowledge, there should be little or no developmental improvement for unfamiliar characters in Cowan, Ricker et al. (2015), for which none of the groups had prior knowledge. Clearly, that was not the outcome. The initial result was that performance improved across age groups for both types of materials. It was true that performance was higher for English letters than for unfamiliar characters and climbed more quickly across age groups; knowledge contributed to performance profoundly. Moreover, there was an interaction between the materials and the age group. The basis of the interaction appeared to be that some of the children in the youngest age group did not know their letters well; they revealed a capacity of less than 1 English letter and did not show much of an advantage for English letters over unfamiliar characters. With those children omitted, the interaction between materials and age group was eliminated. Cowan, Ricker et al. then examined the normalized results, which revealed the improvement from one year to the next in standard deviation units for each type of stimulus material. The developmental progression was quite similar and statistically indistinguishable for the two types of materials (Figure 7). Thus, provided that participants in all groups have sufficient basic knowledge of English letters, knowledge cannot explain the developmental increase in performance (see also the second column of panels in Figure 5). The study also showed comparable loss in each group as the retention interval increased to $10 \mathrm{~s}$. In sum, though there is an obvious increases in knowledge across the elementary school years and beyond, the results show that it cannot be the sole basis of working memory development.

\section{The Factor of Attentional Filtering}

\section{Evidence for the relation of attentional filtering at encoding to working}

memory-A visual array recognition procedure has been used to show the potential relation between selective filtering and working memory in young adults. Specifically, Vogel, McCollough, and Machizawa (2005) found that the event-related potential signature of a memory load showed a different pattern in participants with low versus high working memory performance. High-span adults showed similar patterns of brain activity for sets of 2 relevant targets (e.g., the orientations of green bars) no matter whether these were 
presented alone or along with 2 irrelevant items (e.g., the orientations of red bars). In contrast, low-span adults apparently did not filter out the irrelevant items when the arrays were presented and showed a pattern of brain activity that was similar for, on one hand, 2 relevant items presented along with 2 irrelevant items and, on the other hand, 4 relevant items presented alone. This suggested that in lower-span individuals, all items were allowed into working memory, imposing a task of filtering at the time of recall. In the terms of Braver (2012), the high spans had a proactive performance strategy, filtering out the irrelevant items at the time of encoding; whereas the low spans had a reactive performance strategy, filtering out the irrelevant items only when that was unavoidable, at the time of test.

Yet, it is not clear how general the finding is, of filtering at the time of stimulus presentation as the basis of working memory differences. The procedure of Vogel et al. (2005) is complex because the electrophysiological measure of working memory load requires that participants attend to only one of two visual fields, so that performance depends on selectivity in some way on every trial, and not just on trials with differently-colored distractors.

Providing a simpler index of filtering and working memory capacity, Gold et al. (2006) used a behavioral procedure in which participants received arrays with multiple types of objects (e.g., red and green bars). The task in this example was to remember the orientations of the bars (horizontal or vertical), but they were of unequal importance. A participant could be tested on the red bars on $75 \%$ of the trials and on the green bars on $25 \%$ of the trials. Given the difference in priority, the smart allocation of attention would favor the more-often-tested (in this example, red) bars. A measure of capacity was the estimate of the number of red and green bars in working memory, but a measure of strategic allocation of attention (i.e., processing efficiency) was the extent of a difference in performance favoring the moreoften-tested bars. Surprisingly, schizophrenic participants were as good as control participants at allocating attention, but nevertheless remembered far fewer bars overall. Mall, Morey, Wolf, and Lehnert (2014) set up a situation in normal young adults in which participants could entirely ignore one type of object; eye movements were recorded as a measure of the degree to which individuals looked at the irrelevant items. In agreement with the notion seen in Gold et al., that filtering does not in fact underlie individual differences, individuals with relatively poor working memory did not look at irrelevant items any more than other individuals (but see Fukuda \& Vogel, 2011 for caution).

\section{Childhood development of working memory with selective filtering controlled}

- It is clear that many functions of selective attention improve throughout childhood (Rueda, 2013), although it is not always clear if the observed improvements are entirely maturational and causal or if some of them can be viewed as consequences of other developmental changes (Ristic \& Enns, 2015). In any case, in several recent studies we have investigated the role of attentional filtering on working memory development in childhood, as an extension of the method that Gold et al. (2006) used in adults. The results suggest that the maturation of filtering abilities cannot explain working memory capacity development in the elementary school years (Cowan, AuBuchon, Gilchrist, Ricker, \& Saults, 2011; Cowan, Morey, AuBuchon, Zwilling, \& Gilchrist, 2010). Cowan et al. (2010) presented arrays with 
two differently-colored circles and two differently-colored triangles or, on other trials, with three of each shape. (In other trial blocks, various numbers of objects in only one shape were presented.) The array was followed by a probe item to be judged same or different compared to the corresponding array item. The task was placed in the context of a cover story in which each colored shape represented a child in a classroom (the array); the response was to indicate by mouse click where, in the classroom, the probe "child" belonged or, if the "child" did not belong anywhere in the "classroom," to click the door icon to send the "child" to the principal. These responses yielded a rich set of conditions depending on the type of probe, but the responses were also later combined to form hits (correct indications that something changed between the probe and the array item) and false alarms (incorrect indications that something changed), allowing an application of Cowan's (2001) $k$ formula for items in working memory.

The attention conditions of Cowan et al. (2010) varied by trial block. In different blocks, participants received one shape only, were tested on the colors of one shape on $100 \%$ of the trials, were tested on one shape $80 \%$ of the time and the other shape $20 \%$ of the time, or were tested on each of the two shapes $50 \%$ of the time. It was found that the number of items of a shape included in working memory varied systematically with the attention condition: the more likely it was that a shape would be tested, the more attention was allocated to it. For arrays with only two items in the tested shape, this allocation of attention was just as good for children in the youngest age group (6-8 years, Grades $1 \& 2$ ) as it was for older children and adults. This can be seen in the third cluster of bars in the bottom panel of Figure 5. Yet, children in the youngest age group remembered far fewer array objects than did the older age groups (Figure 5, top panel, third cluster of bars). This finding points to something other than filtering out of less-relevant stimuli as the basis of developmental change in working memory capacity. The pattern of results in the $80 \%$ vs. $20 \%$ condition was replicated by Cowan, AuBuchon et al. (2011) using a slow, serial presentation of array items, with each colored shape appearing at a unique location and disappearing before the next item was presented $1 \mathrm{~s}$ later (Figure 5, fourth bar cluster).

There was evidence in Cowan et al. (2010), however, that the strategic filtering broke down when the number of array objects was increased to three circles and three triangles. In that situation, children in the youngest age group showed similarly poor performance for all of the split-attention conditions $(80 \%, 50 \%, 20 \%)$, suggesting that they were no longer able to allocate attention to such a fine degree when the task of encoding items into working memory was difficult. Thus, processing and storage shared a resource but processing efficiency was the result of a working memory difference between age groups, not the direct cause of one (for a related finding in adult individual differences, cf. Cusack, Lehmann, Veldsman, \& Mitchell, 2009).

\section{The Factor of Encoding and Consolidation of Items in Working Memory}

\section{Evidence regarding encoding and consolidation of working memory-Some}

work, going back at least to Sperling (1960) and Phillips (1974), has focused on the transfer of information from visual sensory memory into a capacity-limited type of memory. It has been observed that when a visual array is followed shortly afterward by a masking pattern, 
the process of entering items into working memory is disrupted. Entering items into working memory requires about 50 ms/item before a mask (Vogel et al., 2006; Woodman \& Vogel, 2005). Further work showed the importance of free attention even after a mask, because higher-level consolidation continued (Jolicoeur \& Dell'Aqua, 1998; Ricker \& Cowan, 2014). Encoding or consolidation of information into working memory could speed up with development, resulting in more represented information. It would be reasonable to worry that the finding of Cowan et al. (2010) could be the result of poorer encoding or consolidation in young children for brief arrays.

\section{Child developmental evidence on working memory development with} encoding and consolidation controlled-Cowan, AuBuchon et al. (2011) addressed this issue of the potential developmental change in the process of encoding items rapidly into working memory by repeating the $80 \%$ vs. $20 \%$ condition of Cowan et al. (2010), but with a serial, slow, 1 item/s rate of presentation of the colored objects, with two objects of the more-often-tested and two of the less-often-tested shape. It does not appear that the speed of encoding or consolidation can explain the age difference in the number of items stored in working memory in this procedure; the pattern of results was unchanged by the slow, serial presentation. Of course, with other kinds of stimuli for which there is a large age difference in long-term memory content, a major determinant of working memory performance might well be encoding speed or efficiency.

\section{The Factor of Verbal Rehearsal}

Evidence on the role of rehearsal-It has been clear for many years that, as children grow older, beyond about 6 years, they acquire the ability to remember lists better by repeating the items or their names, either overtly or covertly when overt repetition is not practical (Flavell, Beach, \& Chinsky, 1966; Ornstein, Naus, \& Liberty, 1975; Tam, Jarrold, Baddeley, \& Sabatos-DeVito, 2010). This seems like a potent, important contribution to working memory development. The issue addressed here, however, is whether rehearsal can account for development of what otherwise might appear to be an increase in basic storage capacity.

There is evidence that rehearsal may play a role in development. Cowan, Cartwright, Winterowd, and Sherk (1987) tested adults on spoken word span with a secondary, articulatory suppression task preventing rehearsal during the list presentation (repeatedly whispering one word during auditory list presentation) and found that span under these conditions resembled 5-year-old children without suppression, with reduced effects of phonological similarity between items. Note, though, that age differences in the phonological similarity and word length effects can be caused by psychometric scaling issues; when young children attain a lower level of performance on lists of short, phonologically dissimilar items, there is less room for further decreases to result from less favorable stimulus qualities, such as phonological similarity among the list items (Jarrold \& Citroën, 2012; Jarrold \& Hall, 2013). Cowan, Saults, and Morey (2006) found effects of suppression less vulnerable to the psychometric concerns because a complex pattern of results differed between 9-10-year old children versus adults. Suppression in the adults made 
the pattern change strikingly to match the children's pattern, but the adults' results nevertheless occurred at a somewhat higher performance level.

Even for nonverbal materials, it seems clear that the pattern of responding changes as rehearsal develops. For example, Hitch, Halliday, Schaafstal, and Heffernan (1991) showed that memory for line drawings of common objects changed as a verbal code came into play. Children who were 11 years old performed worse if the names of the pictured objects were long to pronounce or if they were phonologically similar to one another, making accurate rehearsal difficult. Children who were 5 years old showed the same pattern only when the task required that the picture names be pronounced or when the experimenter pronounced the names. This finding does not seem vulnerable to the aforementioned psychometric concerns because Hitch et al. adjusted their list lengths to equate performance levels among groups. In sum, then, rehearsal appears to play an important role in the development of working memory.

Often, the materials that have been used to examine visual working memory seem available for verbal rehearsal. Theoretically, for example, adults might transform an array of colored squares into their color names, albeit with some use of spatial memory to preserve the location of each color. In practice, however, given the short presentation time of each stimulus array, it appears that rehearsal does not play much of a role in such circumstances. Morey and Cowan (2004) showed this by administering an array memory task with several different secondary tasks during the retention interval between the array of colored squares and the test probe. Recitation of the participant's own 7-digit telephone number during the retention interval had no effect on performance, whereas recitation from memory of a justseen random 7-digit number did interfere with memory for the visual array. This was taken as evidence that the array is not transformed to a verbal form for retention, but that both the visual array and a random 7-digit number require a common pool of attention for their retention (for related evidence of a common attentional resource for verbal and visual processing, see Vergauwe et al., 2009).

\section{Evidence on the development of capacity with rehearsal controlled-Cowan,}

AuBuchon et al. (2011) carried out several conditions of their visual array task in which the stimuli to be remembered were series of colored shapes. In one condition, the participant was to name the color of each object as it was presented. In another, the participant was to remain silent and, in an articulatory suppression condition, the participant was to say "wait" after each object. In each age group, suppression conferred a disadvantage relative to the other two conditions, which did not differ much. The pattern of development was essentially the same in each condition: there was no age difference in the allocation of attention that favored the $80 \%$-tested shape over the $20 \%$-tested shape, but there was a large developmental increase in the number of items in working memory. The fifth cluster of bars in the bottom panel of Figure 5 shows that the inefficiency in performing the task caused by articulatory suppression did not differ between the groups, probably because covert rehearsal is not an important way to retain these particular stimuli. Thus, it does not appear that the contribution of verbal rehearsal can fully explain the increase in working memory capacity with age in childhood. 


\section{The Factor of the Reinstatement of Context}

Adult evidence on effects of context-In the studies illustrated in Figure 5, like many other studies, the test probe included only a single item, which was either identical to the array item that was in the same location or changed from it. One way in which this test probe theoretically might be processed is for the participant to imagine the entire array and to use that imagined array as a cue to the memory of the item in the location of the probe. Numerous adult studies have shown that there is some memory for the configuration or structure across items, in addition to memory of individual items (e.g., Brady \& Tenenbaum, 2013; Jiang, Olsun, \& Chun, 2000; Woodman, Vecera, \& Luck, 2003; Xu \& Chun, 2007). The tendency to organize random arrangements, which has resulted in the naming the constellations of stars as dippers, scorpions, etc., could contribute to good adult performance on array memory. Perhaps young children's working memory suffers from the poverty of configurational information in memory.

Child developmental evidence with context controlled-The developmental increase in visual working memory performance might occur because young children perceive the array as a collection of isolated objects, whereas adults perceive the array as a configuration. To examine this possibility, Cowan, Saults, and Clark (2015) presented arrays of colored objects (circles, tested on $80 \%$ of the trials, and triangles, tested on the remaining $20 \%$ ). What distinguished this study from previous ones in this developmental series is that the probe was not always just a single colored object as in Cowan et al. (2010); in other trial blocks, the colored probe object was accompanied by markers for the locations of the remaining objects from the original array. These markers were unfilled, uncolored line drawings of the shapes that had occurred in the corresponding positions in the studied array. We hypothesized that this arrangement of stimuli in the probe display could provide a spatial-layout context that would allow first- and second-graders to catch up with older children and adults by helping them to remember the array configuration. We presented the contextual items as line drawings to avoid interference from the non-tested colors, a type of interference seen previously in adults (Wheeler \& Treisman, 2002).

The finding was that the contextual cues were helpful to young children, but only in limited circumstances. When the critical probe item remained the same or changed to a color that was not in the studied array, the contextual cues were of no help to any age group. In other trials, however, the probe was an object that had appeared elsewhere in the studied array (i.e., the probe was the same color and shape as an object that had appeared at a different array location). The correct answer was to indicate where the probed object belonged in the studied array. In this situation, children in the first four grades of elementary school benefitted from the contextual cues, whereas older children and adults did not. Apparently, older participants have a more precise representation of the spatial layout of the studied array, and this extra context helps them locate items in the array and makes the contextual markers unnecessary to identify a probe object's location in the array (cf. Burnett Heyes et al., 2012). In sum, although spatial configuration does improve with development, there is an important component of visual working memory development that cannot be attributed to configuration. 


\section{Development during the School Years: Summary}

The outcomes of the tests for confounding factors, none of which is sufficient to account for working memory development, are summarized in Table 1. It is not easy to get rid of the age difference in working memory performance during the elementary school years. The control of many possible confounding factors, one at a time, did not eliminate the age effect in memory.

\section{Concluding Remarks}

In sympathy with the neo-Piagetians, I believe that working memory development is a key aspects of cognitive growth from infancy to adulthood. Infants have the working memory necessary to begin to represent concepts, and then slowly gain the ability for these concepts to have more parts, or to have themselves represented along with the concepts, or to represent the context for appropriate use of the concepts (Halford et al., 2007). Within that general view, however, there is room for subtly different mechanisms. It could be the number of attention-related slots in working memory that increases with age (the number of separate chunks that can be maintained at once: Cowan, Elliott et al., 2005); or what increases with age may be attention-control-related factors that allow the slots to be filled most usefully (Kane \& Engle, 2003).

To put a practical face on this theoretical distinction, consider a young child who is learning to go trick-or-treating on Halloween. The child does not automatically say the requisite utterances, "trick or treat," "thank you," and "goodbye." These parts are gradually learned (Berko Gleason \& Weintraub, 1976). According to a capacity theory, a young child fails to complete the ritual for a reason that may be similar to why the lengths of utterances in early language are short: because there are not enough slots in working memory to allow more parts of a concept to be represented at once or knitted together. According to the attention control theory, on the other hand, the child may start off with every intent to say the three magic words of the ritual; but when the door opens and the child is confronted with a stranger offering candy, attention shifts and does not prevent the new features of the experience from replacing some of the magic words in working memory. Anecdotally conforming to the latter notion, last year I had the experience of opening the door to find that a young, masked child forgot to let go of the doorknob, following it rather automatically into a house in which he did not know the residents.

In hopes of inspiring future work to compare the capacity-growth versus the growth-ofcontrol hypotheses, an important message of this review is that there is an intrinsic interconnectedness of working memory research on humans at various developmental levels. There is a great need for increased communication between infant and child researchers. If infants and adults can be said to have equivalent chunk capacities, as a first look at the infant literature might suggest, then it seems likely that the childhood trends have to do with some other factor; I have suggested in particular the ability to maintain the appropriate items in the attention-based part of working memory, a process that is more demanding in adult-like procedures than in infant procedures. By this hypothesis, young children's memory should be captured by inappropriate stimuli during the retention or test intervals more easily than older children or adults. If, however, infants and adults do differ in true capacity, then what 
has been observed in children may well include a genuine increase in capacity with age in childhood. This is still a distinct possibility, consistent with one interpretation of the infant literature discussed above.

Regarding the interconnectedness of infant- and child-based research conclusions, it is encouraging when researchers discuss the need to bridge infant and childhood studies, Infants cannot carry out the adult-like procedure, and older children (e.g., perhaps above 5 years) cannot perform the infant procedures without importing a host of strategies unavailable to the infants. Therefore, it may be particularly useful to adapt the infant measures for use with very young children (Keen, 2003) or to find simplifications of the adult procedures that can document a developmental increase in working memory in very early childhood, starting as young as 3 years (cf. Simmering, 2012).

A problem with the capacity-growth hypothesis is that it comes across as a glorified null hypothesis. Thus, if confounding factors are controlled and the age difference in working memory still does not disappear, as my colleagues and I have found repeatedly, then one is tempted to conclude by default that there is a genuine age difference in capacity. In the future, this inferential method could be augmented, inasmuch as there are separate positive markers in studies of functional magnetic resonance imaging for the control of attention, dependent on frontal lobe areas (for a review see Kane \& Engle, 2002), and the indexing of items in working memory for attended items regardless of the modality of those items, more dependent on parietal lobe areas and the intraparietal sulcus specifically (Cowan, Li et al.. 2011; Todd \& Marois, 2004; Majerus et al., 2014; Xu \& Chun, 2006). There is evidence for the representation of the activated portion of long-term memory in association areas, with special functional connectivity between those areas, when they are task-relevant (i.e., comprise activated long-term memory), and the intraparietal sulcus (Emrich, Riggall, LaRocque, \& Postle, 2013; Lewis-Peacock, Drysdale, Oberauer, \& Postle, 2012; Li, Christ, $\&$ Cowan, 2014). There are also related markers of the use of attention to refresh information in working memory (Raye, Johnson, Mitchell, Greene, \& Johnson, 2007). There is a considerable literature on the neurological development of the frontal-parietal network (e.g., Casey, Giedd, \& Thomas, 2000; Clasen, Toga, Rapoport, \& Thompson, 2004; Gogtay et al., 2004; Klingberg, Forssberg, \& Westerberg, 2002; Scherf, Sweeney, \& Luna, 2006; Sowell et al., 2003; Thomason et al., 2009) and when researchers are drawn to these more analytic issues of the mapping of different processes onto the developing brain, the capacitygrowth hypothesis can cease to be seen as only a null hypothesis.

It remains to be determined just how the growth of working memory would be combined with developing knowledge and skills to determine a child's growing potential for comprehension and problem-solving. There has been some disappointment in attempts to improve children's abilities through working memory training (e.g., Melby-Lervåg, \& Hulme, 2013) and this might be expected until we know more about what the mechanisms of working memory development are and what role attention plays.

If we come to understand what principles of working memory help to govern cognitive growth, we may take an important, albeit primitive step toward better educational practices 
and remediation of cognitive disorders, by learning more about how much information is or is not likely to take hold in a particular child's mind in particular circumstances.

\section{Acknowledgments}

This work was completed with support from NIH Grant R01 HD-21338. I thank numerous undergraduate, graduate, and non-student assistants throughout the past 15 years.

\section{References}

Alvarez GA, Cavanagh P. The capacity of visual short term memory is set both by visual information load and by number of objects. Psychological Science. 2004; 15:106-111. [PubMed: 14738517]

Andrews G, Halford GS, Murphy K, Knox K. Integration Of weight and distance information in young children: the role of relational complexity. Cognitive Development. 2009; 24:49-60.

Awh E, Barton B, Vogel EK. Visual working memory represents a fixed number of items regardless of complexity. Psychological Science. 2007; 18:622-628. [PubMed: 17614871]

Baddeley, AD. Working memory. Clarendon Press; Oxford Psychology Series \#11. Oxford: 1986.

Baddeley, AD.; Hitch, G. Working memory. In: Bower, GH., editor. The psychology of learning and motivation. Vol. 8. Academic Press; New York: 1974. p. 47-89.

Baddeley AD, Thomson N, Buchanan M. Word length and the structure of short term memory. Journal of Verbal Learning and Verbal Behavior. 1975; 14:575-589. s.

Baillargeon R, DeVos J. Object permanence in young infants: Further evidence. Child Development. 1991; 62:1227-1246. [PubMed: 1786712]

Baillargeon R, Graber M, Devos J, Black J. Why do young infants fail to search for hidden objects? Cognition. 1990; 36:255-284. [PubMed: 2265529]

Baillargeon R, Spelke E, Wasserman S. Object permanence in five-month-old infants. Cognition. 1985; 20:191-208. [PubMed: 4064606]

Barrouillet P, Portrat S, Camos V. On the law relating processing to storage in working memory. Psychological Review. 2011; 118:175-192. [PubMed: 21480738]

Berko Gleason J, Weintraub S. The acquisition of routines in child language. Language in Society. 1976; 5:129-136.

Blankenship AB. Memory span: a review of the literature. Psychological Bulletin. 1938; 35:1-25.

Bolton TL. The growth of memory in school children. American Journal of Psychology. 1892; 4:362380.

Brady TF, Tenenbaum JB. A probabilistic model of visual working memory: Incorporating higher order regularities into working memory capacity estimates. Psychological Review. 2013; 120:85109. [PubMed: 23230888]

Braver TS. The variable nature of cognitive control: A dual-mechanisms framework. Trends in Cognitive Science. 2012; 16:106-113.

Burnett Heyes S, Zokaei N, van der Staaij I, Bays PM, Husain M. Development of visual working memory precision in childhood. Developmental Science. 2012; 15:528-539. [PubMed: 22709402]

Burtis PJ. Capacity increase and chunking in the development of short-term memory. Journal of Experimental Child Psychology. 1982; 34:387-413. [PubMed: 7153702]

Camos V, Barrouillet P. Developmental change in working memory strategies: from passive maintenance to active refreshing. Developmental Psychology. 2011; 47:898-904. [PubMed: 21417518]

Case, R. Intellectual development: Birth to adulthood. Academic Press; New York: 1985.

Case, R. Capacity based explanations of working memory growth: A brief history and reevaluation. In: Weinert, FE.; Schneider, W., editors. Memory performance and competencies: Issues in growth and development. Erlbaum; Mahwah, NJ: 1995. p. 23-44.

Case R, Kurland DM, Goldberg J. Operational efficiency and the growth of short-term memory span. Journal of Experimental Child Psychology. 1982; 33:386-404. 
Casey BJ, Giedd JN, Thomas KM. Structural and functional brain development and its relation to cognitive development. Biological Psychology. 2000; 54:241-257. [PubMed: 11035225]

Chen Z, Cowan N. Core verbal working memory capacity: The limit in words retained without covert articulation. Quarterly Journal of Experimental Psychology. 2009; 62:1420-1429.

Chi, MTH. Knowledge structures and memory development. In: Siegler, R., editor. Children's thinking: What develops?. Erlbaum; Hillsdale, NJ: 1978.

Choi Y, Luo Y. 13-month-olds' understanding of social interactions. Psychological Science. 2015; 26:274-283. [PubMed: 25630442]

Clasen LS, Toga AW, Rapoport JL, Thompson PM. Dynamic mapping of human cortical development during childhood through early adulthood. PNAS. 2004; 101:8174-8179. [PubMed: 15148381]

Commons ML, Trudeau EJ, Stein SA, Richards SA, Krause SR. Hierarchical complexity of tasks shows the existence of developmental stages. Developmental Review. 1998; 18:237-278.

Corrigan R. Language development as related to stage 6 object permanence development. Journal of Child Language. 1978; 5:173-189.

Cottini M, Pieroni L, Spataro P, Devescovi A, Longobardi E, Rossi-Arnaud C. Feature binding and the processing of global-local shapes in bilingual and monolingual children. Memory \& Cognition. 2015; 43:441-452. [PubMed: 25293690]

Cowan N. Evolving conceptions of memory storage, selective attention, and their mutual constraints within the human information processing system. Psychological Bulletin. 1988; 104:163-191. [PubMed: 3054993]

Cowan, N. An embedded-processes model of working memory. In: Miyake, A.; Shah, P., editors. Models of Working Memory: Mechanisms of active maintenance and executive control. Cambridge University Press; Cambridge, U.K.: 1999. p. 62-101.

Cowan N. The magical number 4 in short-term memory: A reconsideration of mental storage capacity. Behavioral and Brain Sciences. 2001; 24:87-185. [PubMed: 11515286]

Cowan, N. Working memory capacity. Psychology Press; Hove, East Sussex, UK: 2005.

Cowan N. The focus of attention as observed in visual working memory tasks: Making sense of competing claims. Neuropsychologia. 2011; 49:1401-1406. [PubMed: 21277880]

Cowan N. Working memory underpins cognitive development, learning, and education. Educational Psychology Review. 2014; 26:197-223. [PubMed: 25346585]

Cowan, N.; Alloway, T. The development of working memory. In: Courage, M.; Cowan, N., editors. The development of memory in infancy and childhood. Psychology Press; Hove, East Sussex, UK: 2009. p. 303-342.

Cowan N, AuBuchon AM, Gilchrist AL, Ricker TJ, Saults JS. Age differences in visual working memory capacity: Not based on encoding limitations. Developmental Science. 2011; 14:10661074. [PubMed: 21884322]

Cowan N, Saults JS, Blume CL. Central and peripheral components of working memory storage. Journal of Experimental Psychology: General. 2014; 143:1806-1836. [PubMed: 24867488]

Cowan N, Cartwright C, Winterowd C, Sherk M. An adult model of preschool children's speech memory. Memory \& Cognition. 1987; 15:511-517. [PubMed: 3695945]

Cowan N, Donnell K, Saults JS. A list-length constraint on incidental item-to-item associations. Psychonomic Bulletin \& Review. 2013; 20:1253-1258. [PubMed: 23653420]

Cowan N, Elliott EM, Saults JS, Nugent LD, Bomb P, Hismjatullina A. Rethinking speed theories of cognitive development: Increasing the rate of recall without affecting accuracy. Psychological Science. 2006; 17:67-73. [PubMed: 16371146]

Cowan N, Elliott EM, Saults JS. Kail R, Reese H. The search for what is fundamental in the development of working memory. Advances in Child Development and Behavior. 2002; 29:1-49. [PubMed: 11957571]

Cowan N, Elliott EM, Saults JS, Morey CC, Mattox S, Hismjatullina A, Conway ARA. On the capacity of attention: Its estimation and its role in working memory and cognitive aptitudes. Cognitive Psychology. 2005; 51:42-100. [PubMed: 16039935] 
Cowan N, Fristoe NM, Elliott EM, Brunner RP, Saults JS. Scope of attention, control of attention, and intelligence in children and adults. Memory \& Cognition. 2006; 34:1754-1768. [PubMed: 17489300]

Cowan N, Johnson TD, Saults JS. Capacity limits in list item recognition: Evidence from proactive interference. Memory. 2005; 13:293-299. [PubMed: 15952261]

Cowan N, Leavitt LA. The developmental course of two children who could talk backward five years ago. Journal of Child Language. 1987; 14:393-395. [PubMed: 3611251]

Cowan N, Li D, Moffitt A, Becker TM, Martin EA, Saults JS, Christ SE. A neural region of abstract working memory. Journal of Cognitive Neuroscience. 2011; 23:2852-2863. [PubMed: 21261453]

Cowan N, Morey CC, AuBuchon AM, Zwilling CE, Gilchrist AL. Seven-year-olds allocate attention like adults unless working memory is overloaded. Developmental Science. 2010; 13:120-133. [PubMed: 20121868]

Cowan N, Nugent LD, Elliott EM, Ponomarev I, Saults JS. The role of attention in the development of short-term memory: Age differences in the verbal span of apprehension. Child Development. 1999; 70:1082-1097. [PubMed: 10546336]

Cowan N, Nugent LD, Elliott EM, Saults JS. Persistence of memory for ignored lists of digits: Areas of developmental constancy and change. Journal of Experimental Child Psychology. 2000; 76:151-172. [PubMed: 10788307]

Cowan N, Ricker TJ, Clark KM, Hinrichs GA, Glass BA. Knowledge cannot explain the developmental growth of working memory capacity. Developmental Science. 2015; 18:132-145 [PubMed: 24942111]

Cowan N, Rouder JN, Blume CL, Saults JS. Models of verbal working memory capacity: What does it take to make them work? Psychological Review. 2012; 119:480-499. [PubMed: 22486726]

Cowan N, Saults JS, Clark KM. Exploring age differences in visual working memory capacity: Is there a contribution of memory for configuration? Journal of Experimental Child Psychology. 2015; 135:72-85. [PubMed: 25841172]

Cowan N, Saults JS, Morey CC. Development of working memory for verbal-spatial associations. Journal of Memory and Language. 2006; 55:274-289. [PubMed: 17387377]

Cusack R, Lehmann M, Veldsman M, Mitchell DJ. Encoding strategy and not visual working memory capacity correlates with intelligence. Psychonomic Bulletin \& Review. 2009; 16:641-647. [PubMed: 19648446]

Darwin CJ, Turvey MT, Crowder RG. An auditory analogue of the Sperling partial report procedure: Evidence for brief auditory storage. Cognitive Psychology. 1972; 3:255-267.

Demetriou A, Christou C, Spanoudis G, Platsidou M. The development of mental processing: Efficiency, working memory, and thinking. Monographs of the Society of Research in Child Development. 2002; 67 Serial Number 268.

Dempster FN. Memory span and short term memory capacity: A developmental study. Journal of Experimental Child Psychology. 1978; 26:419-431.

Dempster FN. Memory span: Sources of individual and developmental differences. Psychological Bulletin. 1981; 89:63-100.

Ebbinghaus, H. Memory: A contribution to experimental psychology. Ruger, HA.; Bussenius, CE., editors. Teachers College, Columbia University; New York: 1885 / 1913. Translated by(Originally in German, Ueber das gedächtnis: Untersuchen zur experimentellen psychologie)

Emrich SM, Riggall AC, LaRocque JJ, Postle BR. Distributed patterns of activity in sensory cortex reflect the precision of multiple items maintained in visual short-term memory. The Journal of Neuroscience. 2013; 33:6516-6523. [PubMed: 23575849]

Engle RW, Tuholski SW, Laughlin JE, Conway ARA. Working memory, short-term memory, and general fluid intelligence: a latent-variable approach. Journal of experimental psychology: General. 1999; 128:309-331. [PubMed: 10513398]

Fancher, RE. Pioneers of psychology. WW Norton \& Co; New York: 1979.

Feigenson L, Halberda J. Conceptual knowledge increases infants' memory capacity. PNAS. 2008; 105:9926-9930. [PubMed: 18626025]

Fiebelkorn IC, Saalmann YB, Kastner S. Rhythmic sampling within and between objects despite sustained attention at a cued location. Current Biology. 2013; 23:2553-2558. [PubMed: 24316204] 
Fischbein, E. Intuition in science and mathematics: An educational approach (Vol. 5). Springer Science \& Business Media; 1987.

Fischer KW. A theory of cognitive development: The control and construction of hierarchies of skills. Psychological Review. 1980; 87:477-531.

Flavell JH, Beach DH, Chinsky JM. Spontaneous verbal rehearsal in a memory task as a function of age. Child Development. 1966; 37:283-299. [PubMed: 5941895]

Fukuda K, Vogel EK. Individual differences in recovery time from attentional capture. Psychological Science. 2011; 22:361-368. [PubMed: 21310945]

Gaillard V, Barrouillet P, Jarrold C, Camos V. Developmental differences in working memory: Where do they come from? Journal Of Experimental Child Psychology. 2011; 110:469-479. [PubMed: 21664622]

Gathercole SE, Baddeley AD. Phonological memory deficits in language disordered children: Is there a causal connection? Journal of Memory and Language. 1990; 29:336-360.

Gathercole SE, Pickering SJ, Ambridge B, Wearing H. The structure of working memory from 4 to 15 years of age. Developmental Psychology. 2004; 40:177-190. [PubMed: 14979759]

Geary, DC. The origin of mind: Evolution of brain, cognition, and general intelligence. American Psychological Association; Washington, D.C.: 2004.

Gelman R, Meck E. Preschoolers' counting: Principles before skill. Cognition. 1983; 13:343-359. [PubMed: 6683141]

Gilchrist AL, Cowan N, Naveh-Benjamin M. Investigating the childhood development of working memory using sentences: New evidence for the growth of chunk capacity. Journal of Experimental Child Psychology. 2009; 104:252-265. [PubMed: 19539305]

Gogtay N, Giedd JN, Lusk L, Hayashi KM, Greenstein D, Vaituzis AC, Nugent TF, Herman DH, Clasen LS, Toga AW, Rapoport JL, Thompson PM. Dynamic mapping of human cortical development during childhood through early adulthood. PNAS. 2004; 101:8174-8179. [PubMed: 15148381]

Gold JM, Fuller RL, Robinson BM, McMahon RP, Braun EL, Luck SJ. Intact attentional control of working memory encoding in schizophrenia. Journal of Abnormal Psychology. 2006; 115:658673. [PubMed: 17100524]

Greeno JG, Riley MS, Gelman R. Conceptual competence and children's counting. Cognitive Psychology. 1984; 16:94-143.

Guttentag RE. The mental effort requirement of cumulative rehearsal: A developmental study. Journal of Experimental Child Psychology. 1984; 37:92-106.

Halford, GS. Children's understanding: The development of mental models. Erlbaum; Hillsdale, NJ: 1993.

Halford GS, Baker R, McCredden JE, Bain JD. How many variables can humans process? Psychological Science. 2005; 16:70-76. [PubMed: 15660854]

Halford GS, Cowan N, Andrews G. Separating cognitive capacity from knowledge: A new hypothesis. Trends in Cognitive Sciences. 2007; 11:236-242. [PubMed: 17475538]

Halford GS, Wilson WH, Phillips S. Processing capacity defined by relational complexity: Implications for comparative, developmental, and cognitive psychology. Behavioral and Brain Sciences. 1998; 21:803-865. [PubMed: 10191879]

Hardman KO, Cowan N. Remembering complex objects in visual working memory: Do capacity limits restrict objects or features? Journal of Experimental Psychology. Learning, Memory, and Cognition. 2015; 41:325-347.

Hitch GJ, Halliday MS, Schaafstal AM, Heffernan TM. Speech, "inner speech," and the development of short term memory: Effects of picture labeling on recall. Journal of Experimental Child Psychology. 1991; 51:220-234. [PubMed: 2033361]

Hood B, Cole-Davies B, Dias M. Looking and search measures of object knowledge in pre-school children. Developmental Psychology. 2003; 39:61-70. [PubMed: 12518809]

Hulme C, Muir C. Developmental changes in speech rate and memory span: A causal relationship? British Journal of Developmental Psychology. 1985; 3:175-181.

Jacobs J. Experiments on "Prehension. Mind. 1887; 12:75-79. 
James, W. The principles of psychology. Henry Holt; NY: 1890.

Jarrold, C.; Bayliss, DM. Variation in working memory due to typical and atypical development. In: Conway, ARA.; Jarrold, C.; Kane, MJ.; Miyake, A.; Towse, JN., editors. Variation in working memory. Oxford University Press; Oxford: 2007. p. 134-161.

Jarrold C, Citroën R. Reevaluating key evidence for the development of rehearsal: Phonological similarity effects in children are subject to proportional scaling artifacts. Developmental Psychology. 2013; 49:837-847. [PubMed: 22662766]

Jarrold C, Hall D. The Development of Rehearsal in Verbal Short-Term Memory. Child Development Perspectives. 2013; 7:182-186.

Jevons WS. The power of numerical discrimination. Nature. 1871; 3:281-282.

Jiang Y, Olson IR, Chun MM. Organization of visual short-term memory. Journal of Experimental Psychology: Learning, Memory, \& Cognition. 2000; 26:683-702.

Johnson MH. The inhibition of automatic saccades in early infancy. Developmental Psychobiology. 1995; 28:281-291. [PubMed: 7672460]

Jolicoeur P, Dell'Acqua R. The demonstration of short-term consolidation. Cognitive Psychology. 1998; 36:138-202. [PubMed: 9721199]

Kahn JV. Utility of the Uzgiris and Hunt Scales of Sensorimotor Development with severely and profoundly retarded children. American Journal of Mental Deficiency. 1976; 80:663-665. [PubMed: 961731]

Káldy Z, Sigala N. The neural mechanisms of object working memory: what is where in the infant brain? Neuroscience and Biobehavioral Reviews. 2004; 28:113-121. [PubMed: 15172760]

Kane MJ, Engle RW. Working-memory capacity, proactive interference, and divided attention: Limits on long-term memory retrieval. Journal of Experimental Psychology: Learning, Memory, and Cognition. 2000; 26:336-358.

Kane MJ, Engle RW. The role of prefrontal cortex in working-memory capacity, executive attention, and general fluid intelligence: An individual-differences perspective. Psychonomic Bulletin \& Review. 2002; 9:637-671. [PubMed: 12613671]

Kane MJ, Engle RW. Working-memory capacity and the control of attention: The contributions of goal neglect, response competition, and task set to Stroop interference. Journal of Experimental Psychology: General. 2003; 132:47-70. [PubMed: 12656297]

Keen R. Representation of objects and events why do infants look so smart and toddlers look so dumb? Current Directions in Psychological Science. 2003; 12:79-83.

Kibbe MM. Varieties of visual working memory representation in infancy and beyond. Current Directions in Psychological Science. in press.

Kibbe MM, Leslie AM. What do infants remember when they forget? Location and identity in 6Month-olds' memory for objects. Psychological Science. 2011; 22:1500-1505. [PubMed: 22095976]

Kibbe MM, Leslie AM. What's the object of object working memory in infancy? Unraveling 'what' and 'how many'. Cognitive Psychology. 2013; 66:380-404. [PubMed: 23770623]

Klingberg T, Forssberg H, Westerberg H. Increased brain activity in frontal and parietal cortex underlies the development of visuospatial working memory capacity during childhood. Journal Of Cognitive Neuroscience. 2002; 14:1-10. [PubMed: 11798382]

Lewis-Peacock JA, Drysdale AT, Oberauer K, Postle BR. Neural evidence for a distinction between short-term memory and the focus of attention. Journal Of Cognitive Neuroscience. 2012; 24:6179. [PubMed: 21955164]

Li D, Christ SE, Cowan N. Domain-general and domain-specific functional networks in working memory. Neuroimage. 2014; 102:646-656. [PubMed: 25178986]

Lisman JE, Idiart MAP. Storage of $7+2$ short term memories in oscillatory subcycles. Science. 1995; 267:1512-1515. [PubMed: 7878473]

Lisman JE, Jensen O. The theta-gamma neural code. Neuron. 2013; 77:1002-1016. [PubMed: 23522038]

Luck SJ, Vogel EK. The capacity of visual working memory for features and conjunctions. Nature. 1997; 390:279-281. [PubMed: 9384378] 
Luck SJ, Vogel EK. Response from Luck and Vogel. Trends in Cognitive Sciences. 1998; 2:78-80. [PubMed: 21227077]

Ma WJ, Husain M, Bays PM. Changing concepts of working memory. Nature Neuroscience. 2014; 17:347-56. [PubMed: 24569831]

Maehler C, Schuchardt K. Working memory functioning in children with learning disabilities: does intelligence make a difference? Journal of Intellectual Disabilities Research. 2009; 53:3-10.

Majerus S, Cowan N, Péters F, Van Calster L, Phillips C, Schrouff J. Cross-modal decoding of neural patterns associated with working memory: Evidence for attention-based accounts of working memory. Cerebral Cortex. 2014 E-pub ahead of print, doi:10.1093/cercor/bhu189.

Mall JT, Morey CC, Wolf MJ, Lehnert F. Visual selective attention is equally functional for individuals with low and high working memory capacity: Evidence from accuracy and eye movements. Attention, Perception, \& Psychophysics. 2014; 76:1998-2014.

Marti, E.; Rodriguez, C., editors. After Piaget. Transaction Publishers; New Brunswick, NJ: 2012.

Mash C, Novak E, Berthier NE, Keen R. What do two-year-olds understand about hidden-object events? Developmental Psychology. 2006; 42:263-271. [PubMed: 16569165]

McCulloch WS, Pitts W. A logical calculus of the ideas immanent in nervous activity. Bulletin of Mathematical Biophysics. 1943; 5:115-133.

McLaughlin GH. Psycho-logic: A possible alternative to Piaget's formulation. British Journal of Educational Psychology. 1963; 33:61-67.

Melby-Lervåg M, Hulme C. Is working memory training effective? A meta-analytic review. Developmental Psychology. 2013; 49:270-291. [PubMed: 22612437]

Miller GA. The magical number seven, plus or minus two: Some limits on our capacity for processing information. Psychological Review. 1956; 63:81-97. [PubMed: 13310704]

Miller, GA.; Galanter, E.; Pribram, KH. Plans and the structure of behavior. Holt, Rinehart and Winston, Inc; New York: 1960.

Miyake, A.; Shah, P., editors. Models of working memory: Mechanisms of active maintenance and executive control. Cambridge University Press; Cambridge, U.K.: 1999.

Moore MK, Meltzoff AN. Object permanence, imitation, and language development in infancy: Toward a neo-Piagetian perspective on communicative and cognitive development. Communicative and cognitive abilities_Early behavioral assessment. 1978:151-184.

Morey CC, Cowan N. When visual and verbal memories compete: Evidence of cross-domain limits in working memory. Psychonomic Bulletin \& Review. 2004; 11:296-301. [PubMed: 15260196]

Mou Y, Province JM, Luo Y. Can infants make transitive inferences? Cognitive Psychology. 2014; 68:98-112. [PubMed: 24316415]

Nairne JS. A feature model of immediate memory. Memory \& Cognition. 1990; 18:251-269. [PubMed: 2192233]

Newell, A.; Simon, HA. Rand Corp; Santa Monica, CA: 1956. The logic theory machine: A complex information processing system.

Oakes, LM.; Bauer, PJ., editors. Short- and long-term memory in infancy and early childhood: Taking the first steps toward remembering. Oxford University Press; New York, NY: 2007.

Oakes LM, Baumgartner HA, Barrett FS, Messenger IM, Luck SJ. Developmental changes in visual short-term memory in infancy: evidence from eye-tracking. Frontiers In Psychology. 2013; 4:113. doi:10.3389/fpsyg.2013.00697. [PubMed: 23382719]

Oberauer K, Lewandowsky S, Farrell S, Jarrold C, Greaves M. Modeling working memory: An interference model of complex span. Psychonomic Bulletin \& Review. 2012; 19:779-819. [PubMed: 22715024]

Ornstein PA, Naus MJ, Liberty C. Rehearsal and organizational processes in children(s memory. Child Development. 1975; 46:818-830.

Pascual-Leone J. A mathematical model for the transition rule in Piaget's developmental stages. Acta Psychologica. 1970; 32:301-345.

Pascual-Leone, J.; Johnson, J. A developmental theory of mental attention: Its applications to measurement and task analysis. In: Barrouillet, P.; Gaillard, V., editors. Cognitive development 
and working Memory: From neoPiagetian to cognitive approaches. Psychology Press; Hove, UK: 2011. p. 13-46.

Pascual-Leone J, Smith J. The encoding and decoding of symbols by children: A new experimental paradigm and a neo Piagetian model. Journal of Experimental Child Psychology. 1969; 8:328355.

Phillips WA. On the distinction between sensory storage and short-term visual memory. Perception \& Psychophysics. 1974; 16:283-290.

Piaget, J. The essential Piaget. Gruber, HE.; Voneche, JJ., editors. Basic Books; New York: 1977.

Piaget, J.; Inhelder, B. The psychology of the child. Weaver, Helen, editor. Basic Books; New York: 1969. Translated from the French by

Raye CL, Johnson MK, Mitchell KJ, Greene EJ, Johnson MR. Refreshing: A minimal executive function. Cortex. 2007; 43:135-145. [PubMed: 17334213]

Ricker TJ, Cowan N. Differences between presentation methods in working memory procedures: A matter of working memory consolidation. Journal of Experimental Psychology: Learning, Memory, and Cognition. 2014; 40:417-428.

Riggs KJ, McTaggart J, Simpson A, Freeman RPJ. Changes in the capacity of visual working memory in 5- to 10-year-olds. Journal of Experimental Child Psychology. 2006; 95:18-26. [PubMed: 16678845]

Riggs KJ, Simpson A, Potts T. The development of visual short-term memory for multifeature items during middle childhood. Journal of Experimental Child Psychology. 2011; 108:802-809. [PubMed: 21257180]

Ristic J, Enns JT. The changing face of attentional development. Current Directions in Psychological Science. 2015; 24:24-31.

Ross-Sheehy S, Oakes LM, Luck SJ. The development of visual short-term memory capacity in infants. Child Development. 2003; 74:1807-1822. [PubMed: 14669897]

Rouder JN, Morey RD, Cowan N, Zwilling CE, Morey CC, Pratte MS. An assessment of fixedcapacity models of visual working memory. Proceedings of the National Academy of Sciences (PNAS). 2008; 105:5975-5979.

Rueda, MR. Development of attention. In: Ochsner, K.; Kosslyn, SM., editors. The Oxford handbook of cognitive neuroscience. Vol. 1. Oxford University Press; New York, NY: 2013. p. 296-316.Core Topics

Scherf KS, Sweeney JA, Luna B. Brain Basis of Developmental Change in Visuospatial Working Memory. Journal Of Cognitive Neuroscience. 2006; 18:1045-1058. [PubMed: 16839280]

Schutte AR, Spencer JP. Tests of the dynamic field theory and the spatial precision hypothesis: Capturing a qualitative developmental transition in spatial working memory. Journal of Experimental Psychology: Human Perception and Performance. 2009; 35:1698-1725. [PubMed: 19968430]

Shimi A, Nobre AC, Astle D, Scerif G. Orienting Attention within Visual Short-Term Memory: Development and Mechanisms. Child Development. 2014; 85:578-592. [PubMed: 23937596]

Shipstead Z, Engle RW. Interference within the focus of attention: Working memory tasks reflect more than temporary maintenance. Journal of Experimental Psychology: Learning, Memory, and Cognition. 2013; 39:277-289.

Siegel L, Linder B. Short term memory processes in children with reading and arithmetic learning disabilities. Developmental Psychology. 1984; 20:200-207.

Siegel LS, Ryan EB. The development of working memory in normally achieving and subtypes of learning disabled children. Child Development. 1989; 60:973-980. [PubMed: 2758890]

Siegel M, Warden MR, Miller EK. Phase-dependent neuronal coding of objects in short-term memory. Proceedings of the National Academy of Science (PNAS). 2009; 15:21341-21346.

Siegler RS. Cognitive variability: A key to understanding cognitive development. Current Directions in Psychological Science. 1994; 3:1-5.

Simmering VR. The development of visual working memory capacity during early childhood. Journal of Experimental Child Psychology. 2012; 111:695-707. [PubMed: 22099167] 
Simmering VR, Patterson R. Models provide specificity: Testing a proposed mechanism of visual working memory capacity development. Cognitive Development. 2012; 27:419-439. [PubMed: 23204645]

Sowell ER, Peterson BS, Thompson PM, Welcome SE, Henkenius AL, Toga AW. Mapping cortical change across the human life span. Nature Neuroscience. 2003; 6:309-315. [PubMed: 12548289]

Spelke ES, Breinlinger K, Macomber J, Jacobson K. Origins of knowledge. Psychological Review. 1992; 99:605. [PubMed: 1454901]

Sperling G. The information available in brief visual presentations. Psychological Monographs. 1960; 74 (Whole No. 498.).

Swanson HL, Sachse-Lee C. Mathematical problem solving and working memory in children with learning disabilities: Both executive and phonological processes are important. Journal of Experimenal Child Psychology. 2001; 79:294-321.

Tam H, Jarrold C, Baddeley AD, Sabatos-DeVito M. The development of memory maintenance: Children's use of phonological rehearsal and attentional refreshment in working memory tasks. Journal of Experimental Child Psychology. 2010; 107:306-324. [PubMed: 20576275]

Thomason ME, Race E, Burrows B, Whitfield-Gabrieli S, Glover GH, Gabrieli JE. Development of spatial and verbal working memory capacity in the human brain. Journal Of Cognitive Neuroscience. 2009; 21:316-332. [PubMed: 18510448]

Todd JJ, Marois R. Capacity limit of visual short-term memory in human posterior parietal cortex. Nature. 2004; 428:751-754. [PubMed: 15085133]

Towse JN, Hitch GJ, Hamilton Z, Peacock K, Hutton UMZ. Working memory period: The endurance of mental representations. Quarterly Journal of Experimental Psychology A: Human Experimental Psychology. 2005; 58A:547571.

Treisman AM. Monitoring and storage of irrelevant messages in selective attention. Journal of Verbal Learning and Verbal Behavior. 1964; 3:449-459.

Vergauwe E, Barrouillet P, Camos V. Visual and spatial working memory are not that dissociated after all: A time-based resource-sharing account. Journal of Experimental Psychology: Learning, Memory, and Cognition. 2009; 35:1012-1028.

Vogel EK, McCollough AW, Machizawa MG. Neural measures reveal individual differences in controlling access to working memory. Nature. 2005; 438:500-503. [PubMed: 16306992]

Vogel EK, Woodman GF, Luck SJ. The time course of consolidation in visual working memory. Journal of Experimental Psychology: Human Perception and Performance. 2006; 32:1436-1451. [PubMed: 17154783]

Wheeler ME, Treisman AM. Binding in short term visual memory. Journal of Experimental Psychology: General. 2002; 131:48-64. [PubMed: 11900102]

Woodman GF, Vecera SP, Luck SJ. Perceptual organization influences visual working memory. Psychonomic Bulletin \& Review. 2003; 10:80-87. [PubMed: 12747493]

Woodman GF, Vogel EK. Fractionating working memory: Consolidation and maintenance are independent processes. Psychological Science. 2005; 16:106-113. [PubMed: 15686576]

Wynn K. Infants' individuation and enumeration of actions. Psychological Science. 1996; 7:164-169.

Xu Y, Chun MM. Dissociable neural mechanisms supporting visual short-term memory for objects. Nature. 2006; 440:91-95. [PubMed: 16382240]

Zhang G, Simon HA. STM capacity for Chinese words and idioms: Chunking and acoustical loop hypotheses. Memory \& Cognition. 1985; 13:193-201. [PubMed: 4046819]

Zhang W, Luck SJ. Discrete fixed-resolution representations in visual working memory. Nature. 2008; 453:23-35.

Zhang W, Luck SJ. The number and quality of representations in working memory. Psychological Science. 2011; 22:1434-1441. [PubMed: 21987693]

Zosh JM, Feigenson L. Array heterogeneity prevents catastrophic forgetting in infants. Cognition. 2015; 136:365-380. [PubMed: 25543889] 


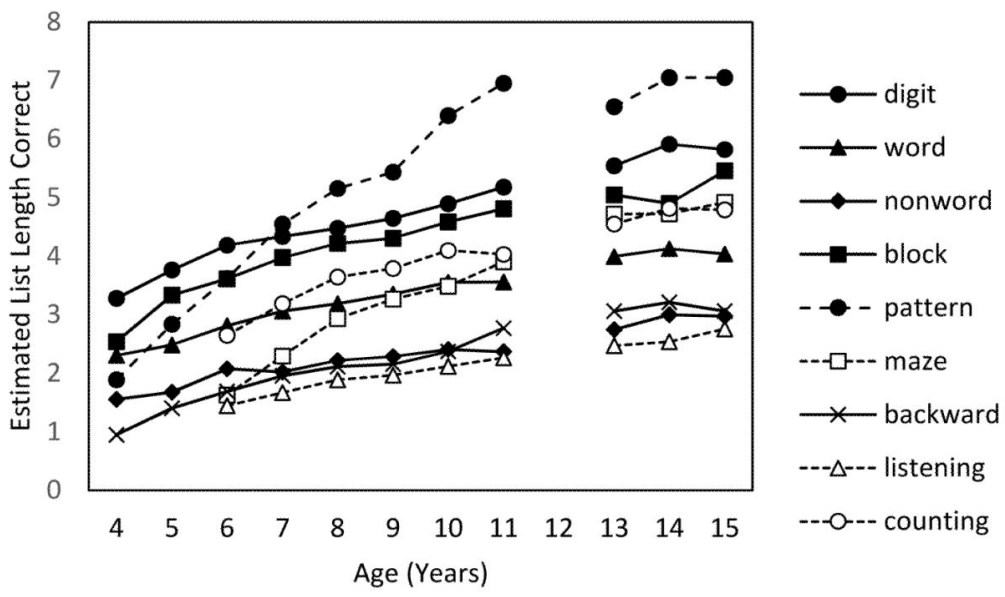

Figure 1.

Estimated items of various types recalled by children as a function of age, based on a rescoring of the results from Gathercole, Pickering, Ambridge, \& Wearing (2004, Table 1). Based on the number of trials per length that they used and their scoring system, each mean from the table was divided by 6 except for visual pattern memory scores, which were divided by 3 . The steeper development of visual patterns and mazes compared to other modalities could be related to the development of the ability to form a coherent spatial configuration from the items. 


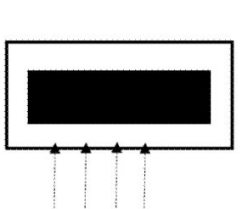

A, B, C, D

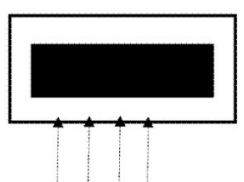

A, B, C, D
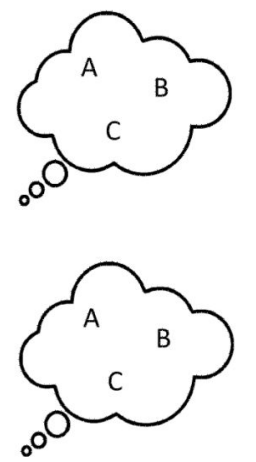

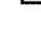

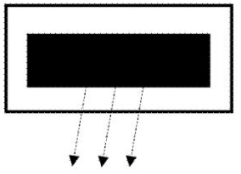

A, C, D

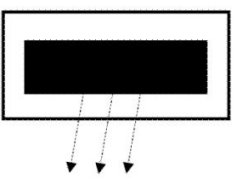

A, C, D
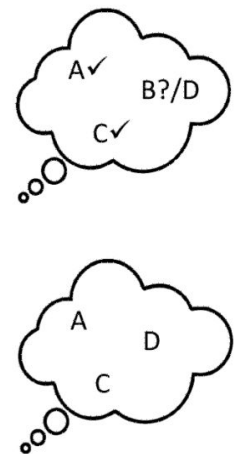

Figure 2.

Illustration of hypothetical processing modes in the hidden-objects infant procedure of Zosh and Feigenson (2015) with three items in working memory. Each row progresses from left to right. Four objects schematically labeled A-D are hidden in a box, and three of them have been retrieved by the illustrated point in time. In the top row, the infant compares all of the retrieved objects to the objects in the attention-based part of working memory. This method, however, would leave the infant unsatisfied after three withdrawals on $75 \%$ of the trials because not all three of the remembered objects would be withdrawn in the first three draws. In the trial shown, for example, Objects $\mathrm{A}, \mathrm{C}$, and D have been retrieved but D was not in working memory so the child presumably would keep looking for the fourth object in working memory, B. The bottom row reflects the proposed alternative strategy with no comparison process; Object D replaces Object B in the attention-based part of working memory, so B is forgotten and the infant is satisfied with three objects. This process more closely matches the obtained results unless the infant's capacities averaged less than 2 items (see text for details). 


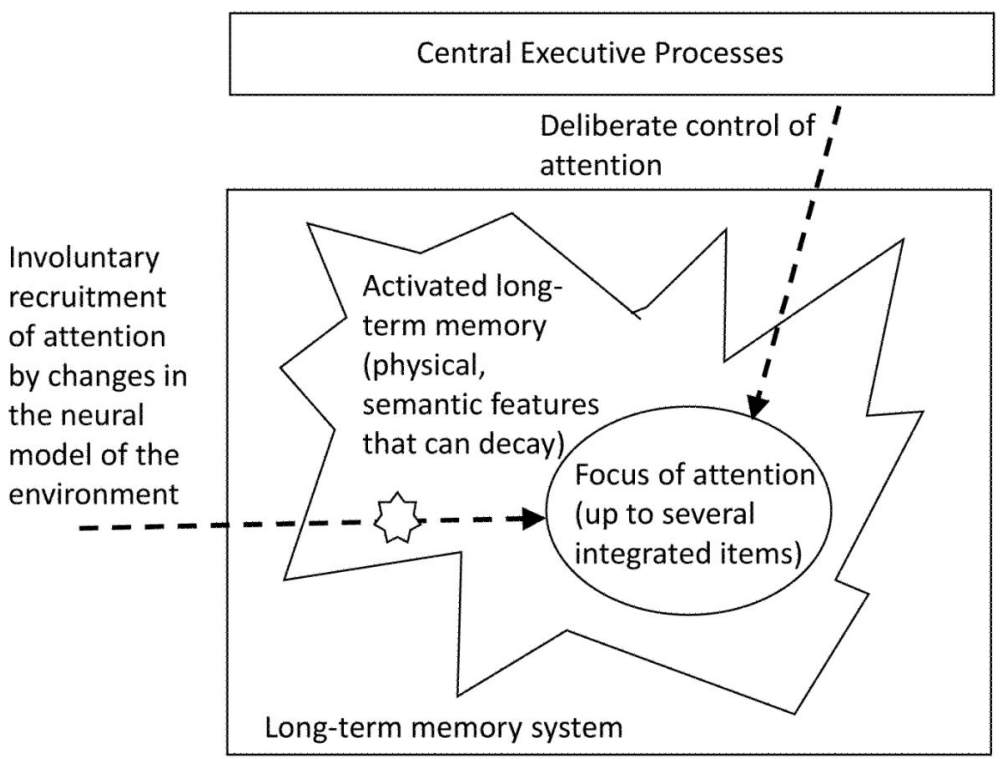

Figure 3.

Schematic view of the embedded-processes theoretical framework of Cowan $(1988,1999)$. 

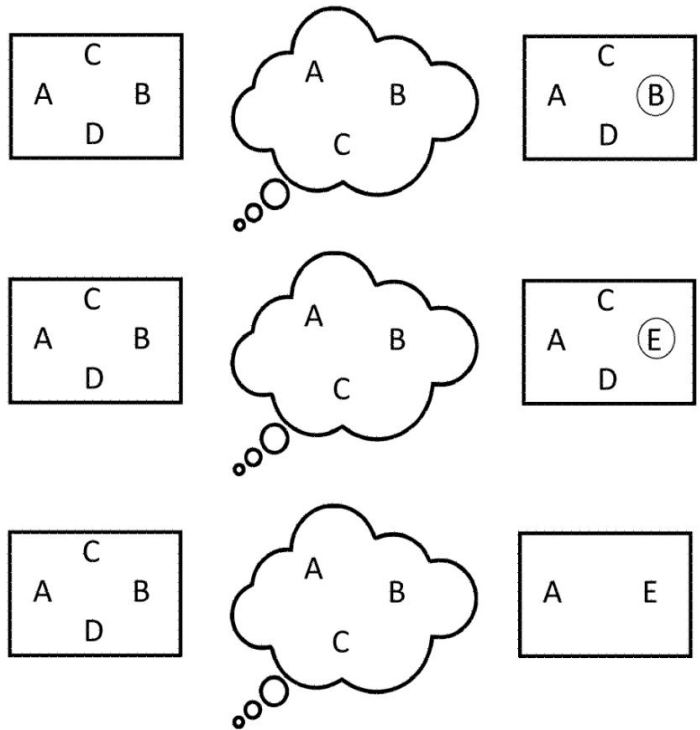
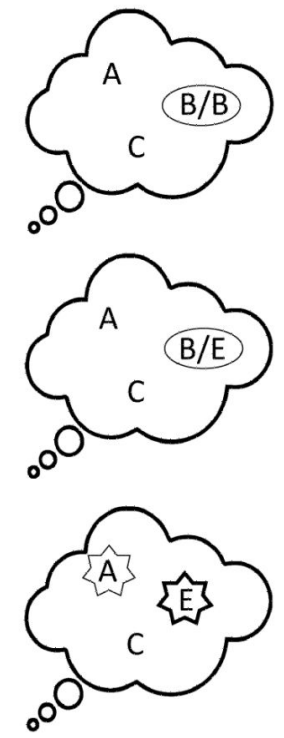

Figure 4.

Illustration of proposed processing modes in change-detection procedures with a capacity of three working memory items. Each row progresses from left to right. The top row shows adult-like processing when four items, schematically labeled A-D here, are presented; three of them are encoded in the participant's attention-based part of working memory; and one of the items that is probed happens to be present in this part of working memory. The probe is explicitly compared to the corresponding array item. The middle row shows adult-like performance in the same sequence, but with a changed probe; the probe is judged different from the corresponding array item in working memory. The bottom row shows a strategy that can be used in the one-shot infant procedure of Oakes, Baumgartner, Barrett, Messenger, and Luck (2013). Because two probes are presented and one comes from the array, the two probes can often be distinguished on the basis of relative activation based on novelty. The bold shape represents more activation. No explicit comparison with the array in focal attention is needed. 

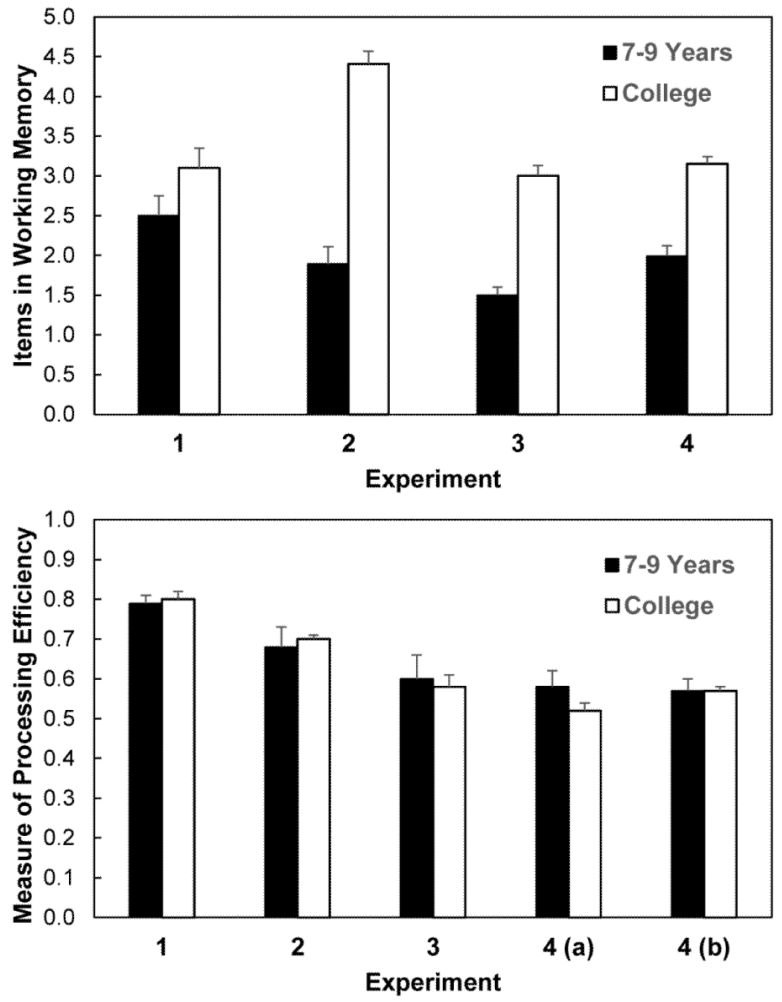

Figure 5.

Data from 4 experiments illustrating age differences in the estimated number of items in working memory (top panel) despite no difference in the relevant measure of processing efficiency (bottom panel). Experiments listed on the $\mathrm{x}$ axis: $1=$ Gilchrist et al. (2009); $2=$ Cowan, Ricker et al. (2015, 1-s delay); 3=Cowan et al. (2010); and 4=Cowan, AuBuchon et al. (2011). The top panel reflects memory for (1) at least one content word from each short, spoken sentence to indicate access to that sentence within 4-sentence lists; (2) letters from a spatial array; and (3-4) colored objects from a spatial array. The atypically high capacity of adults in Experiment 2 is likely to reflect the covert verbal rehearsal of letters. In the bottom panel, the measures of processing efficiency are (1) the proportion of words recalled from accessed sentences, i.e. from those sentences with at least one content word recalled; (2) memory for letters divided by the sum of memory for letters and unfamiliar characters; ( 3 , 4a) memory for the colors of the more-relevant shape divided by memory of the colors of both shapes together, based on 4-item arrays, silent condition; and (4b) memory for colors from trials with silence divided by memory for colors from both silent and speak-anirrelevant-word conditions summed. Error bars are standard errors. 

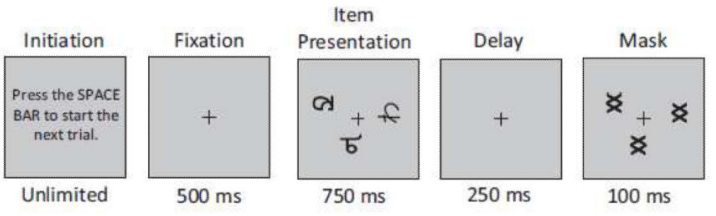

Retention

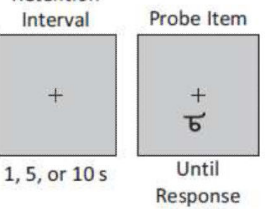

Figure 6.

Stimuli in an unfamiliar-character trial of an experiment on the role of knowledge in visual working memory development. Reproduced from Cowan et al. (2015, Developmental Science, Figure 1). 


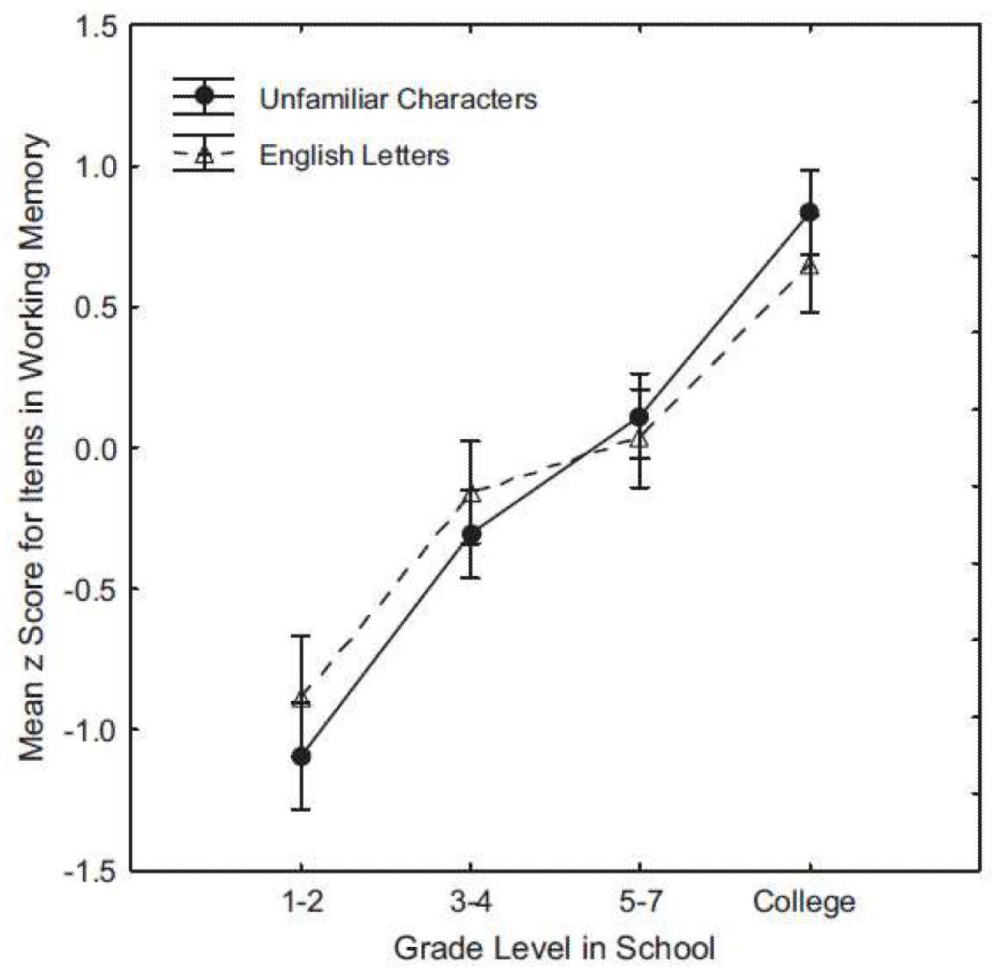

Figure 7.

Standardized scores for capacity in the unfamiliar-character and English-letter conditions of an experiment on the role of knowledge in visual working memory development, at a 1-s retention interval. In terms of these scores, the two types of materials show indistinguishable rates of improvement across age groups. Reproduced from Cowan et al. (2015, Developmental Science, Figure 4). Most children in Grades 1-2 are 6-8 years old. 
Table 1

Factors other than working memory capacity that could account for the childhood development of working memory, studies that have examined these factors, methods used in these studies, and main findings

\begin{tabular}{|c|c|c|c|}
\hline Factor & Study & Method & Conclusion \\
\hline $\begin{array}{l}\text { 1. Could more } \\
\text { knowledge result in } \\
\text { larger chunks and } \\
\text { could these chunks } \\
\text { explain the growth of } \\
\text { visual array memory } \\
\text { capacity? }\end{array}$ & Cowan, Ricker, Clark, Hinrichs, \& Glass (2015) & $\begin{array}{l}\text { Recognition of items } \\
\text { from visual arrays of } \\
\text { English letters or of } \\
\text { unfamiliar characters. } \\
\text { Elementary school } \\
\text { children ( } 7-13 \text { years) and } \\
\text { college. }\end{array}$ & $\begin{array}{l}\text { Knowledge hypothesis } \\
\text { disconfirmed. Excluding } \\
\text { some of the first-grade } \\
\text { children who did not } \\
\text { know letters well, } \\
\text { normalized growth in } \\
\text { recognition was similar } \\
\text { for English letters and } \\
\text { unfamiliar characters. }\end{array}$ \\
\hline $\begin{array}{l}\text { 2. Could more } \\
\text { knowledge result in } \\
\text { larger chunks and } \\
\text { could these chunks } \\
\text { explain the growth of } \\
\text { spoken list memory } \\
\text { capacity? }\end{array}$ & Gilchrist, Cowan, Naveh-Benjamin (2009) & $\begin{array}{l}\text { Verbatim recall of lists } \\
\text { of simple, unrelated } \\
\text { spoken sentences. } \\
\text { Access to sentences } \\
\text { measures capacity; } \\
\text { completion of accessed } \\
\text { sentences shows } \\
\text { chunking. Ages 7, 12, } \\
\text { and college students. }\end{array}$ & $\begin{array}{l}\text { Knowledge hypothesis } \\
\text { disconfirmed. Even } \\
\text { though at all ages, } ~ 80 \% \\
\text { of words from accessed } \\
\text { sentences were recalled } \\
\text { (good sentence } \\
\text { knowledge), the number } \\
\text { of sentences at least } \\
\text { partly recalled grew } \\
\text { developmentally. }\end{array}$ \\
\hline $\begin{array}{l}\text { 3. With development, } \\
\text { could the better ability } \\
\text { to filter out irrelevant } \\
\text { information allow } \\
\text { more working } \\
\text { memory space for } \\
\text { relevant items? }\end{array}$ & Cowan, Morey, AuBuchon, Zwilling, \& Gilchrist (2010) & $\begin{array}{l}\text { Recognition of items } \\
\text { from mixed arrays. In } \\
\text { the critical condition, } \\
80 \% \text { of trials the color of } \\
\text { a circle is probed; } 20 \% \\
\text { of trials, the color of a } \\
\text { triangle is probed. } \\
\text { Children } 7-8,12-13 \text {, } \\
\text { college students. }\end{array}$ & $\begin{array}{l}\text { Filtering hypothesis } \\
\text { disconfirmed. With only } \\
4 \text { items in an array ( } 2 \\
\text { circles, } 2 \text { triangles), } \\
\text { participants of all age } \\
\text { groups filtered out less- } \\
\text { relevant shapes equally. } \\
\text { Yet, the younger } \\
\text { children remembered far } \\
\text { fewer items from the } \\
\text { arrays. }\end{array}$ \\
\hline $\begin{array}{l}\text { 4. Could the } \\
\text { developing ability } \\
\text { rapidly to encode } \\
\text { items from an array } \\
\text { assist recognition? }\end{array}$ & Cowan, AuBuchon, Gilchrist, Ricker, \& Saults (2011) & $\begin{array}{l}\text { Method as in \#3 } \\
\text { (Cowan et al., 2010) } \\
\text { except that } \\
\text { items were presented one } \\
\text { at a time at a slow, serial, } \\
1 \text { per second rate. } \\
\text { Children } 7-8,12-13 \text {, and } \\
\text { college students. }\end{array}$ & $\begin{array}{l}\text { Encoding hypothesis } \\
\text { disconfirmed. Results } \\
\text { were the same as in \#3 } \\
\text { even though the potential } \\
\text { encoding difficulty was } \\
\text { removed. }\end{array}$ \\
\hline $\begin{array}{l}\text { 5. Could the } \\
\text { developing ability to } \\
\text { rehearse nonverbal } \\
\text { stimuli verbally allow } \\
\text { better recognition? }\end{array}$ & $\begin{array}{l}\text { Same study as } \\
\text { immediately } \\
\text { above, \#4 (Cowan, AuBuchon et al., 2011) }\end{array}$ & $\begin{array}{l}\text { Method as explained just } \\
\text { above but with the need } \\
\text { to say "wait" after each } \\
\text { item to interrupt } \\
\text { rehearsal }\end{array}$ & $\begin{array}{l}\text { Rehearsal hypothesis } \\
\text { disconfirmed. There } \\
\text { was still a developmental } \\
\text { difference in the number } \\
\text { of items recognized. }\end{array}$ \\
\hline $\begin{array}{l}\text { 6. Could the ability to } \\
\text { reinstate the context of } \\
\text { a recognition cue } \\
\text { improve with age? }\end{array}$ & Cowan, Saults, \& Clark (2015) & $\begin{array}{l}\text { Arrays of colored } \\
\text { squares were followed } \\
\text { by a probe square for } \\
\text { recognition, which was } \\
\text { sometimes surrounded } \\
\text { by markers of where the } \\
\text { other squares had been. } \\
\text { Children } 7-8,9-10,12- \\
13 \text {, and college. }\end{array}$ & $\begin{array}{l}\text { Context hypothesis } \\
\text { disconfirmed. Younger } \\
\text { children benefited from } \\
\text { the contextual markers, } \\
\text { but only for trials in } \\
\text { which the precision of } \\
\text { spatial knowledge was } \\
\text { important. }\end{array}$ \\
\hline
\end{tabular}

